\title{
Impact of Tat Genetic Variation on HIV-1 Disease
}

\author{
Luna Li, ${ }^{1,2}$ Satinder Dahiya,, 2 Sandhya Kortagere,, 2 \\ Benjamas Aiamkitsumrit,, ${ }^{1,2}$ David Cunningham, ${ }^{1,2}$ Vanessa Pirrone, ${ }^{1,2}$ \\ Michael R. Nonnemacher, ${ }^{1,2}$ and Brian Wigdahl ${ }^{1,2}$
${ }^{1}$ Department of Microbiology and Immunology, Drexel University College of Medicine, 245 N. 15th Street, MS no. 1013A, Philadelphia, PA 19102, USA
${ }^{2}$ Center for Molecular Virology and Translational Neuroscience, Institute for Molecular Medicine and Infectious Disease, Drexel University College of Medicine, 245 N. 15th Street, MS no. 1013A, Philadelphia, PA 19102, USA

Correspondence should be addressed to Brian Wigdahl, brian.wigdahl@drexelmed.edu

Received 22 February 2012; Accepted 14 May 2012

Academic Editor: Nicola Coppola

Copyright ( $) 2012$ Luna Li et al. This is an open access article distributed under the Creative Commons Attribution License, which permits unrestricted use, distribution, and reproduction in any medium, provided the original work is properly cited.

The human immunodeficiency virus type 1 (HIV-1) promoter or long-terminal repeat (LTR) regulates viral gene expression by interacting with multiple viral and host factors. The viral transactivator protein Tat plays an important role in transcriptional activation of HIV-1 gene expression. Functional domains of Tat and its interaction with transactivation response element RNA and cellular transcription factors have been examined. Genetic variation within tat of different HIV-1 subtypes has been shown to affect the interaction of the viral transactivator with cellular and/or viral proteins, influencing the overall level of transcriptional activation as well as its action as a neurotoxic protein. Consequently, the genetic variability within tat may impact the molecular architecture of functional domains of the Tat protein that may impact HIV pathogenesis and disease. Tat as a therapeutic target for anti-HIV drugs has also been discussed.

\section{Introduction}

The human immunodeficiency virus type 1 (HIV-1) is the causative agent of acquired immunodeficiency syndrome (AIDS). The HIV-1 genome is about $9.8 \mathrm{~kb}$ in length, including two viral long-terminal repeats (LTRs) located at both ends when integrated into the host genome. The genome also includes genes that encode for the structural proteins ([Gag], $[\mathrm{Pol}]$, and $[\mathrm{Env}])$, regulatory proteins (Tat and $[\mathrm{Rev}]$ ), and accessory proteins ([Vpu], [Vpr], [Vif], and [Nef]). The HIV-1 transactivator of transcription (Tat) protein is an early regulatory protein containing from 86 to 106 amino acids in length with a molecular weight of approximately 14 to $16 \mathrm{kDa}$. Tat is a multifunctional protein that has been proposed to contribute to several pathological consequences of HIV-1 infection. Tat not only plays an important role in viral transcription and replication, it is also capable of inducing the expression of a variety of cellular genes as well as acting as a neurotoxic protein. In this review, the functions of Tat and molecular diversity in Tat are addressed. Moreover, the interaction of Tat with the viral LTR and cellular factors are documented and discussed. Because of its pivotal role in viral replication and disease pathogenesis, Tat and the cellular pathways targeted by Tat could be potential targets for new anti-HIV drugs. Therapeutic strategies that have focused on this topic are also reviewed.

\section{Functional Domains of the Transactivator Protein Tat}

Tat is a 14 to $16 \mathrm{kDa}$ nuclear protein. It is a multifunctional protein, which is essential for the productive and processive transcription driven from the HIV-1 LTR promoter, and is required for overall productive viral replication $[1,2]$. It is a 101-amino acid protein encoded by two exons: the first exon encodes amino acids 1 to 72; the second encodes residues from 73 to 101 (Figure 1) [3]. Most clinical HIV-1 isolates of Tat include 101 amino acids, whereas a few isolates contain from 86 to 106 amino acids, with the second exon coding from 14 to 34 residues at the $\mathrm{C}$ terminus of the protein [4]. The HIV-1 IIIB Tat used in many in vitro experiments contains 86 amino acids, corresponding to HIV-1 


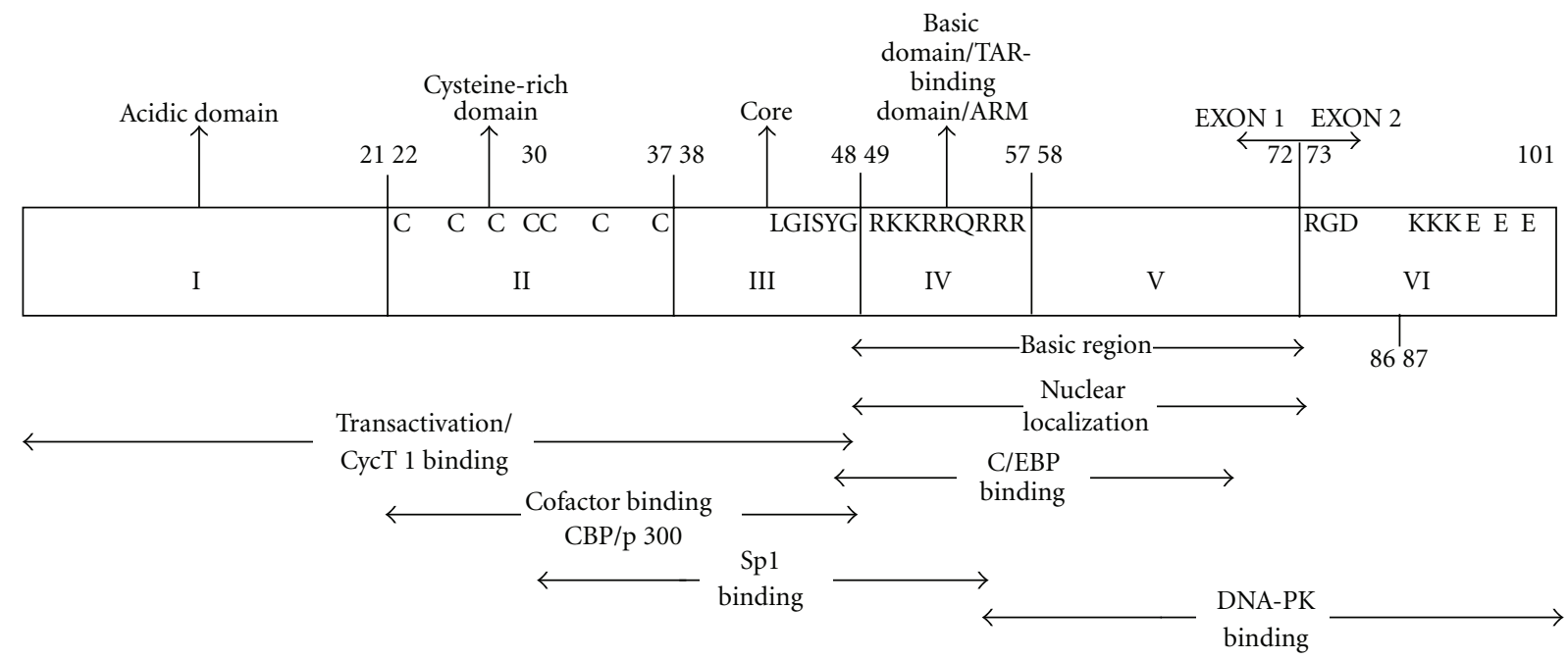

FIGURE 1: Schematic representation of HIV-1 Tat with locations of the six main domains indicated. Within each domain, important amino acid residues are designated. In addition, known functions of the domains or interactions with the protein involved in transcription are also highlighted.

(strain BRU) or a closely related sequence from the HXB2 HIV-1 infectious molecular clone [5, 6]. This 86-amino acid configuration of Tat is the most frequently used form for laboratory investigations; however, it must be noted that it represents a truncated protein when compared to Tat from many clinical isolates. Several studies have established that HIV-1 Tat maintains the 101-amino acid composition as previously reviewed [7]. The more truncated 86 -amino acid version of Tat appears to be functional [4], but functions like modulation of host cell cytoskeleton modifications [8] and perhaps optimal replication in cells of the monocytemacrophage lineage have been attributed to the second exon. Also, the fact that most clinical isolates preserve the full 101amino acid form is indicative of the functional relevance of the second exon in an in vivo setting.

Tat has been divided into six different functional domains (Figure 1) [3, 4, 9]. The N-terminal domain (residues 1-21, also known as the acidic domain) is a proline-rich region containing a conserved tryptophan residue and a number of acidic amino acids. This region is able to form an $\alpha$ helix and is tolerant of numerous single-residue changes without severe compromise in protein function. The second domain (residues 21-37, also referred to as the cysteinerich domain) contains a highly conserved cysteine-rich tract including seven cysteines at positions $22,25,27,30,31,34$, and 37 , four of which are responsible for the formation of disulfide bridges; changes in any one of six of the seven cysteines significantly affect Tat function [10]. The third domain (residues 38-48) has a hydrophobic core sequence: ${ }_{43} \mathrm{LGISYG}_{48}$. The first three domains (amino acid 1-48) comprise the minimal region for Tat transactivation capability. Within this region, genetic variation resulting in changes in amino acids from 1 to 21 is typically tolerated; however, changes in residues from 22 to 40 are deleterious with respect to transactivation. The fourth domain (residues 49-57, the basic domain) is a positively charged region composed of a well-conserved ${ }_{49} \mathrm{RKKRRQRRR}_{57}$ motif, also known as the arginine-rich motif, or transactivation response element(TAR) binding domain. This region is necessary for Tat nuclear localization, binding to the HIV-1 leader RNA TAR [11-13], and uptaken by other cells $[14,15]$. Studies have also demonstrated that Tat utilizes the basic domain residues from 48 to 60 for the functional internalization into cells $[16,17]$. The fifth domain (residues 58-72) is a glutaminerich region shown to exhibit the greatest degree of genetic variability. The fourth and fifth domains together (residues 49-72) are referred to as the basic region. The sixth domain (amino acid 73-101) encoded by the second exon has been less well characterized but may contribute to viral infectivity and binding to cell-surface integrins [18-20]. Two short motifs have been identified in the $\mathrm{C}$ terminus of Tat: the RGD (arg-gly-asp) motif, which is a ligand for several integrins, and the highly conserved ESKKKVE motif, which may be related to optimal HIV-1 replication in vivo $[18,21]$. Although the transactivation domain has been localized to Tat exon I, Tat exon II also plays a role in kappa-light-chainenhancer of activated B cell-(NF- $\kappa$ B) dependent control of HIV-1 transcription in T cells [22]. The glutamic acid residues 92,94 , and 96 or lysine residues 88,89 , and 90 within the Tat exon II exhibit a critical role in activating NF- $\kappa$ B, transactivating the HIV-1 LTR, and enhancing HIV-1 replication in $\mathrm{T}$ cells.

\section{Basal and Stimulated Transactivation Driven by the HIV-1 LTR}

The HIV-1 LTRs are generated during the process of reverse transcription and located on each end of the proviral DNA when the provirus is integrated into the host genome. The LTR is approximately 640 base pairs in length and divided into the unique $5^{\prime}$ (U5) and $3^{\prime}$ (U3) regions as well as the repeat region (Figure 2). LTR sequences include four 


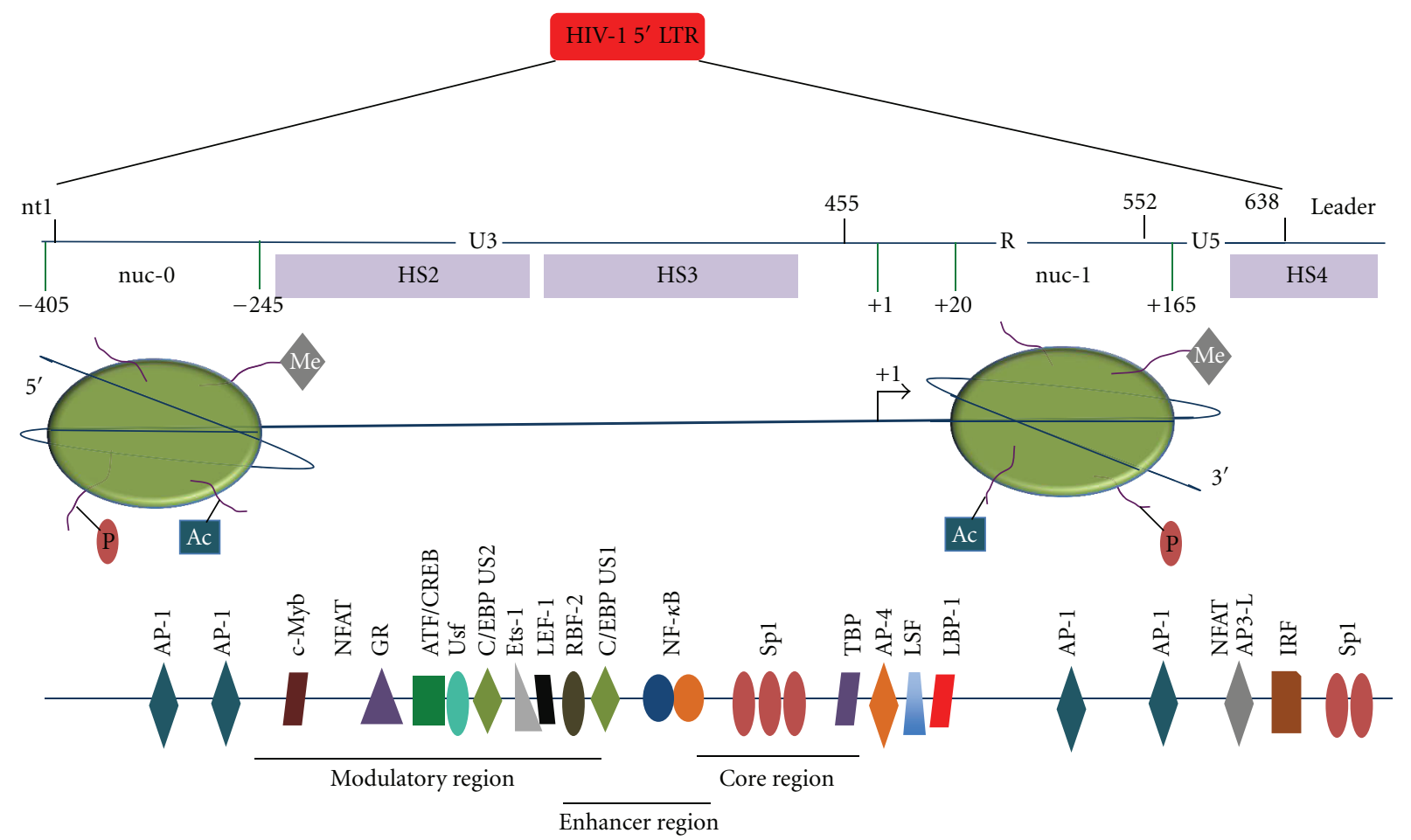

FIGURE 2: Molecular architecture of the HIV-1 long-terminal repeat. The viral promoter, the long-terminal repeat (LTR), can be divided into the U3, R, and U5 regions. Upon integration, the LTR presents stretches of DNase I hypersensitivity sites (shown as HS2, HS3, and HS4) as a result of the well-defined, conversed positioning of the two nucleosomes; nuc-0 and nuc-1. This architecture results in exposure of stretches of DNA extremely rich in transcription factor-binding sites that include different regulatory proteins in the process of HIV-1 transcription. These factors respond to various extracellular and intracellular stimuli, resulting in upregulation/downregulation of specific downstream transcription factors that act via binding to their respective binding sites in the LTR. Also, positioning of nuc-1 is crucial because it is present immediately downstream of the start site $(+1)$; this nucleosome needs to be remodeled for active processive transcription to ensue from the LTR. Moreover, modifications like acetylation, phosphorylation, and methylation of histone tails regulate LTR-directed transcription. The HIV-1 Tat protein regulates the chromatin environment via interactions with several components including methyltransferases, acetyltransferases, and a number of transcription factors in addition to binding to the TAR element in nascent HIV-1 RNA.

functional regulatory regions with respect to the control of HIV-1 transcription: TAR element, core promoter, enhancer region, and modulatory region [47]. A multitude of HIV-1 promoter regulatory elements are located within the U3 region of the $5^{\prime}$ LTR and drive the production of HIV-1 mRNA that codes for proteins involved in regulating viral replication as well as the assembly and release of infectious progeny virus. The core region of the LTR is composed of the TATAA box, which is located 29-24 nucleotides upstream of the transcriptional start site, and specificity protein $(\mathrm{Sp})$ binding sites, which are three tandem GC-rich binding sites $(-45$ to -77$)$ interacting with transcription factors Sp1 through Sp4. The TATAA box binds TATAA-binding protein in association with a number of other proteins that comprise the RNA polymerase II (pol II) transcription complex for transcription initiation and elongation [4850]. The enhancer element is primarily composed of two copies of 10 -base pair binding sites for NF- $\kappa$ Bs and related proteins [51]. The modulatory region, which is in the $5^{\prime}$ end of the U3 region, contains binding sites for many factors, including CCAAT/enhancer-binding protein (C/EBP) factors [52], activating transcription factor/cyclic AMP response element-binding protein (ATF/CREB) [53], nuclear factor of activated T cells (NFAT) [54], and a number of other proteins, depending on cell phenotype, differentiation status, and state of activation (Figure 2) [55-58].

The integrated proviral DNA interfaces with the normal molecular architecture of the host chromatin, which is assembled into nucleosomes. Each nucleosome contains a protein core made of eight histone molecules (H2A, H2B, $\mathrm{H} 3$, and $\mathrm{H} 4$ ) and 146 nucleotide-long double-stranded DNA wrapped around it [59]. Independent of the integration site, two nucleosomes (designated nuc- 0 and nuc-1) are precisely organized on the HIV-1 viral promoter DNA (Figure 2) [60, 61]. In a transcriptionally quiescent state, nuc- 0 is positioned at nucleotide from -405 to -245 relative to the transcriptional start site, and nuc-1 is positioned at nucleotide from +20 to +165 relative to the transcriptional start site (Figure 2). These wrapped regions define two open nucleosome-free regions in the viral DNA, extending from -244 to +19 and +166 to +256 relative to the transcription start site (Figure 2). These open regions include the HIV-1 LTR modulatory, enhancer/core region, transcription factorbinding sites for AP3-L, Sp1 [60], and upstream regulatory 
factor (USF) [62], and a region overlapping the primerbinding site immediately downstream of the $5^{\prime}$ LTR [63]. It has been proposed and shown that displacement of nuc1 is a prerequisite for HIV-1 transcription as observed in response to $\mathrm{T}$ cell activation stimuli [60]. Conformation of the nucleosomes is modulated in two ways: (1) posttranslational modifications of N-terminal tails of histones, namely acetylation, phosphorylation, and methylation through factors like histone acetyl transferases (HATs), histone deacetylases (HDACs), histone methyltransferases (HMTs), and kinases and (2) ATP-dependent chromatin remodeling complexes such as $\mathrm{P} 300 / \mathrm{CBP}$-associated factor (PCAF) and the SWI/SNF family [64].

Acetylation of specific lysine residues within the Ntermini of selective core histones by HATs neutralizes positive charges on these amino acids, thereby weakening histoneDNA interactions and making the DNA more "open" or accessible to the transcriptional machinery $[65,66]$. In contrast, recruitment of HDACs results in transcriptional repression. For example, recruitment of histone deacetylase-1 (HDAC1) by NF- $\kappa$ B p50 was found to constitutively maintain nuc- 0 and nuc- 1 in a deacetylated state, thus keeping the chromatin in a condensed state, impairing RNA pol II recruitment and transcriptional initiation (Figure 3) [67]. The importance of HDAC1 has been shown by studies that have proposed a dynamic model for LTR regulation in $\mathrm{T}$ cells by two cellular transcriptional regulators YY1 and LSF [68]. They form a trimeric complex with HDAC1 at a region-spanning nucleotides from -10 to +27 of the HIV-1 LTR. Whereas LSF-1 binds to DNA, YY1 serves as an intermolecular bridge to anchor HDAC1 to this region [68].

Histone methylation can also have a number of effects on transcription. For example, methylation of lysine-9 (K9) on histone-3 (H3) by HMTs has been shown to be linked with transcriptional silencing, just as methylation of $\mathrm{K} 4$ that is associated with activation [69]. Accordingly, maintenance of the heterochromatic state at the integrated HIV-1 promoter has been shown to be mediated by the methyltransferase Suv39H1, which specifically mediates H3-K9 trimethylation, and the heterochromatin protein- $1 \gamma$, which has been shown to recruit HMT [70-72]. Apart from methylation of histone, hypermethylation of CpG sites found within the HIV-1 LTR has also been shown to repress basal and activation-induced promoter activity, thereby inducing a state of latency [73].

Activation of HIV-1 transcription is mediated by host cell transcription factors and viral proteins via interactions with the cis-regulating elements in the LTR, along with protein-protein interactions in the regulatory pathway(s) [3]. LTR-basal transcription is driven primarily through cellular transcription factors such as Sp1 and NF- $\kappa$ B, which help recruit the RNA pol II complex to the transcriptional start site. This process can be enhanced during cell activation stimulated by a number of cytokines [74]. The availability of host cell transcription factors and viral proteins regulates HIV-1 gene expression in the context of specific cell types, cell-cycle regulation, cellular differentiation, and cellular activation [75]. Sequestration of two critical transcription factors, NF- $\kappa \mathrm{B}$ and NFAT, in the cytoplasm of resting $\mathrm{CD} 4^{+}$ $\mathrm{T}$ cells contributes to the repressive state of the HIV-1
LTR in these cells [76]. The paucity of these factors within the nucleus is reversed in response to activation signals. $\mathrm{T}$ cell receptor (TCR) cross-linking, cytokine stimulation (e.g., TNF- $\alpha$, IL-7), or mitogens (e.g., protein kinase C activators like the phorbol ester PMA and prostratin) lead to nuclear translocation of these molecules and subsequent binding to overlapping cognate sites in the HIV-1 LTR, thereby upregulating basal as well as Tat-mediated promoter activity (Figure 3). TCR ligation also induces transcription and heterodimerization of the c-jun/c-fos complex AP- 1 , which is absent in resting $\mathrm{T}$ cells [77] and synergizes with NFAT and NF- $\kappa \mathrm{B}$ to promote HIV-1 gene expression. Basal and stimulated transcription produces predominantly short RNA as a result of the hypophosphorylated state of RNA pol II. However, an increasing number of longer transcripts encode for a pool of viral regulatory proteins, especially Tat, that eventually feedback to enhance the next stage of viral transcription, designated Tat-mediated transcription.

\section{Tat-Mediated Transactivation of the HIV-1 LTR through Cyclin-Dependent Kinase 9 and Cyclin T1}

HIV-1 transcription involves an early, Tat-independent phase and a late, Tat-dependent phase, and transactivation of the viral genome is a critical step in the viral replication cycle $[3,78]$. In the presence of Tat, LTR-mediated transcriptional activity can be enhanced tens or hundreds of fold [79-82], whereas viral replication falls to nearly undetectable levels in the absence of Tat, and short transcripts (30-50 nucleotides) predominate [83-85]. Tat is a unique transcription factor in that it binds to the "UCU" bulge of the TAR, a cisacting RNA enhancer element within the $5^{\prime}$ end of all viral transcripts. The TAR is located immediately downstream of the transcriptional start site in the HIV-1 LTR, encompassing nucleotides from +1 to $+59[86,87]$, and is required for the function of the viral transactivator protein Tat. The Tat-TAR interaction acts to tether Tat and allow its interaction with the basal transcriptional machinery, thus increasing viral transcription and elongation $[88,89]$. In a mature transcript, TAR adopts a hairpin structure including a six-nucleotide loop, a trinucleotide pyrimidine bulge, and an extensive duplex structure [86]. U23, in the bulge, is critical for Tat binding $[2,13,90]$; the other two neighboring residues C24 and U25 can be replaced by other nucleotides without affecting Tat binding. Another two regions above the bulge (G26-C39 and A27-U38) and one region below (A22-U40) also contribute to Tat binding $[2,13,90]$. Although the loop structure does not appear to be required for Tat binding, the residues in the loop have been shown to be required for Tat transactivation activity [90].

Specifically, HIV-1 Tat has been shown to associate with the P-TEFb, which is composed of cyclin T1 and cyclindependent kinase 9 (CDK9) [24, 91, 92]. This association occurs in a sequential manner. Once bound, CDK9 has been shown to phosphorylate the carboxy-terminal domain (CTD) of RNA pol II and promote transcription elongation $[24,91,93]$. Therefore, the lack of HIV-1 gene expression in 


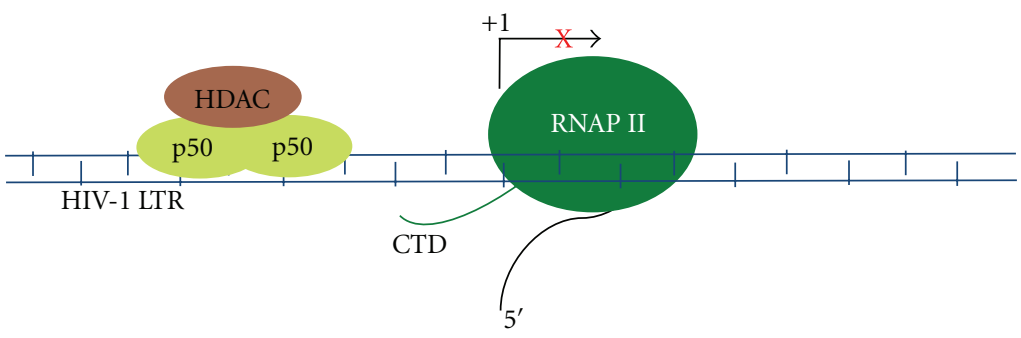

(a)

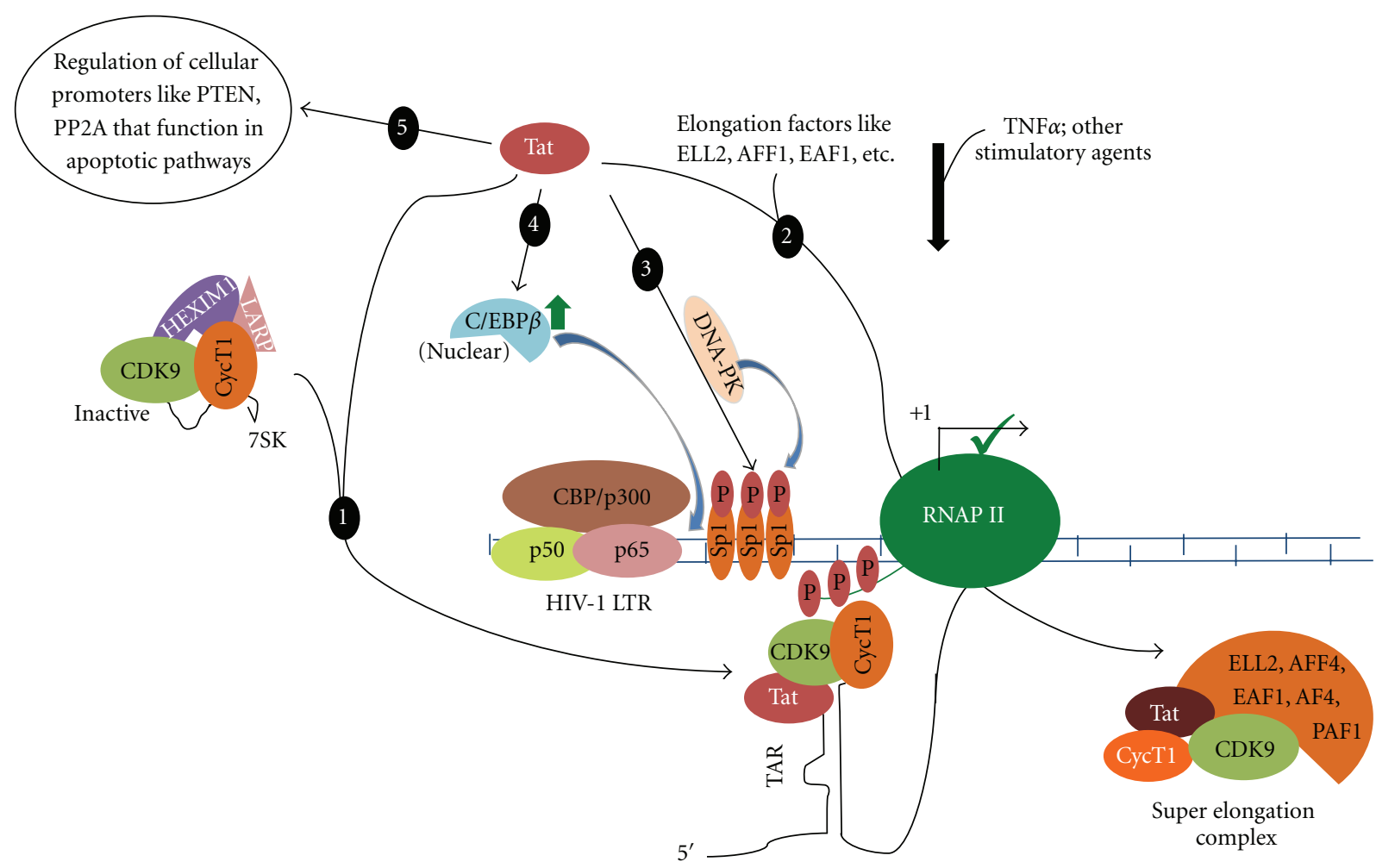

(b)

Figure 3: Functions of Tat. Tat plays a crucial role in synthesis of full-length HIV-1 mRNA transcripts. In the absence of Tat, the viral promoter remains latent with NF- $\kappa \mathrm{B}$ (p50 homodimers) and histone deacetylase complexes (HDACs) maintaining a repressive chromatin environment by deacetylating the histones (a). Thus, RNA polymerase-(RNAPII) driven transcription is not progressive- and full-length HIV-1 transcripts are not synthesized. (b) Under a cellular stimulation environment, the latent state is overcome by recruitment of CBP/p300 complex to the viral promoter, the LTR. The Tat protein translocates to the nucleus and triggers a release of P-TEFb (CDK9/CycT1) from an inactive complex with HEXIM1, LARP, and 7SK RNA (1). The active P-TEFb in complex with Tat then interacts with the stem-loop structure (TAR) in the nascent HIV-1 mRNA's 5' end. This event triggers the phosphorylation of the C-terminal domain (CTD) of RNAPII by CDK9, resulting in productive transcription from the LTR (b). Tat also participates in formation of a "super elongation complex" with factors including ELL2, AFF1, EAF1, and others, which also aids in synthesis of full-length HIV-1 transcripts from the relieved template (2). Tat also recruits another kinase DNA-PK in a ternary complex with Sp1 transcription factor at the LTR (3). This results in phosphorylation of Sp1 and activation of Sp1-mediated LTR-directed transcription. Tat also interacts with $\mathrm{C} / \mathrm{EBP} \beta$ and triggers an increase in the nuclear levels of $\mathrm{C} / \mathrm{EBP} \beta$, again indirectly regulating the transcription of the HIV-1 genome (4). Moreover, Tat also regulates transcription of other cellular promoters of phosphatases like PTEN and PP2A. These play crucial regulatory roles in apoptosis of HIV-1-infected CD4 ${ }^{+}$T cells $(5)$.

latently infected cells might not only arise due to the absence of Tat but also as a result of extremely low levels of CDK9 and cyclin $\mathrm{T} 1$, as observed in resting $\mathrm{CD}^{+} \mathrm{T}$ cells [94]. In addition, mutations in the tat gene, the Tat-responsive element itself, might also contribute to the latent phenotype, as is evident from experiments performed in the U1 [95] and ACH-2 [96] cell lines, respectively. The cyclin T1 subunit of P-TEFb has been shown to interact with the activation domain of Tat and to bind to the central loop $(+30$ to +35$)$ of TAR [92]. Once cyclin T1 binds to Tat, the CycT1-Tat complex has been shown to bind both the bulge and the loop regions of TAR with a higher affinity than Tat alone and to subsequently form the CycT1-Tat-TAR ternary complex $[92,97,98]$. 
With respect to sequence variation within the TAR region, different subtypes have been shown to have distinct TAR motifs, with most of the sequence variation occurring in the stem region [99]. Subtypes A/E and A contain a nucleotide deletion (T25) in the TAR bulge region (T23C24T25) leading to the formation of a two-nucleotide bulge [100-104]. This sequence alteration does not affect subtype $\mathrm{B}$ Tat binding to the subtype E TAR region. However, the studies concerning matched subtype A, A/E, or E TAR and Tat have not been reported [105]. A C-to-T change at position 24 in the bulge has been identified in subtypes $C, D$, F, most of $\mathrm{G}$ bulges, and $50 \%$ of subtype A bulges examined [104]. Additionally, a T-to-C change at position 2 of the loop structure has been consistently observed in subtype $\mathrm{C}$ [106]. Additional functional studies need to be performed to determine the impact of structural differences that may be important in the Tat-TAR-cyclin T1 interactions. Recent investigations have expanded the understanding of Tat-TARcycT1 interactions and have implicated the role of Tat acetylation in modulation of transcriptional elongation [107]. Moreover, mutation analysis of the $\mathrm{N}$ terminal of CycT1 [108] that impairs the transcriptional activity via compromising Tat-TAR-cycT1 interactions has laid the foundation for utilizing this aspect of HIV-1 transcriptional activation in novel therapeutic intervention strategies. These studies also add new aspects that extend our understanding of HIV-1latency; however, adaptability of HIV-1 has hampered the use of these studies to any productive end. Another major issue is that most studies tend to examine these functional aspects of HIV-1 transcription in a subtype-specific manner and studies that encompass these variables are limited. Analyzing large databases of sequence information is still a tedious process, and development of more organized tools will encourage researchers to make better progress in this area.

\section{Interaction of Tat with Other Proteins Involved in Transcription}

The hypophosphorylated form of RNA pol II leads to the production of short RNA molecules (30-50 nucleotides in length including the entire length of the TAR sequence) as a result of premature termination of transcription. However, phosphorylation of the CTD of RNA pol II has been shown to prevent premature termination and promote the efficient elongation and production of full-length HIV-1 RNA transcripts [109]. Phosphorylation of the CTD of RNA pol II has also been shown to be important for the clearance of mediators from RNA pol II [110] (Figure 3). Transcription factor II $\mathrm{H}$ (TFIIH) is a part of the preinitiation complex involved in transcription, and a number of studies have shown that there are combinatorial networks of transcription factors and cofactors, such as P-TEFb, utilized by Tat to activate and repress gene expression $[107,111]$. Tat and P$\mathrm{TEFb}$ are recruited to viral preinitiation complexes prior to RNA transcription and are subsequently transferred to nascent RNA after initiation. In addition to regulating HIV-1 gene expression, Tat is known to be involved in dysregulating cellular function and altering cellular gene expression profiles; however, the mechanism by which Tat affects infected cells continues to be explored.

Tat also functions as a coactivator to recruit histone acetyltransferases, including CBP/p300 and PCAF to the LTR [112]. Tat-recruited HATs presumably acetylate histones in LTR-proximal nucleosomes, remodeling nuc-1, and potentiating transcription $[60,113]$. In addition, Tat itself has been shown to be a substrate for the HAT enzyme activity associated with CBP/p300 and PCAF [114-118]. The HAT activity of $\mathrm{CBP} / \mathrm{p} 300$ can also influence the activity of the NF- $\kappa \mathrm{B}$ p50 subunit. The increased acetylation of p50 leads to an increase in p50 DNA binding and the concomitant transcriptional activation of the HIV-1 promoter [119].

The SWI/SNF complex is another family of proteins that interacts with Tat and plays a role in the regulation of the HIV-1 promoter. The SWI/SNF proteins are integral components of the RNA pol II holoenzyme [120] and have the ability to disrupt DNA-histone contacts and allow access to transcriptional activators $[120,121]$. In the context of HIV-1 transcription, SWI/SNF proteins are required for the transactivation ability of Tat and generation of mature fulllength transcripts. Physical interaction between Tat and the remodeling subunits INI1 and Brm has also been observed $[122,123]$. T cell activation by mitogenic stimuli induces recruitment of SWI/SNF complex subunits Jun-3, BRG-1, and ATF-3 [124]. In particular, BRG-1 has been shown to be recruited to the Ap1-III site located at the 3' boundary of nuc-1 [124]. T cell activation also enhances the endogenous pools of inositol phosphate, increasing the activity of SWI/SNF by a yet-unexplained mechanism [125-127].

Tat has also been shown to facilitate enhanced transcriptional initiation through protein-protein interactions with Sp1 [128] (Figure 3). Tat residues 30-55 contact Sp1 and impact DNA-PK-mediated phosphorylation of Sp1, which increases gene expression driven by the HIV-1 LTR (Figure 3) [129]. Amino acids 56-101 of Tat contain the DNA-PKbinding domain. TFIIH has been shown to be able to bind the transactivation domain of Tat and phosphorylate the CTD of RNA pol II although a number of investigative groups have shown that different subunits of TFIIH may mediate Tat binding [130]. Interestingly, the ability of TFIIH to phosphorylate RNA pol II has been shown to be significantly increased after it was bound to Tat; in turn, the transactivation ability of Tat was enhanced in the presence of TFIIH [84]. Tat has been shown to be specifically associated with Tat-associated kinase, which corresponds to the Drosophila P-TEFb, composed of cyclin T1 and CDK9. Cyclin T1 interacts directly with the activation domain of Tat and has been shown to mediate high affinity and specific binding of Tat to TAR. After Tat binding to cyclin T1, CDK9 is recruited, and then CDK9 phosphorylates CTD of RNA pol II and promotes transcription elongation. Tat is able to effectively antagonize HIV-1 latency and promote active transcription by liberating $\mathrm{P}-\mathrm{TEFb}$ from an inactive 7SK RNP complex. Moreover, Tat is proposed to engage in formation of a "super elongation complex" with elongation factors like ELL2, ENL, AFF4, PAF1, and others as previously reviewed [131] (Figure 3). Meanwhile, efficient transcription elongation of the HIV-1 genome in response to Tat has been 
shown to lead to more Tat synthesis and generate a Tatdependent positive feedback loop. However, mouse cyclin T1 has a cysteine-to-tyrosine substitution at position 261 that may lead to weak binding of mouse cyclin T1 to Tat, resulting in Tat losing the ability to interact with TAR, which results in low transactivation levels. However, changing the tyrosine residue back to cysteine at position 261 renders mouse cyclin T1 fully functional in Tat transactivation, demonstrating the importance of this residue in the transactivation process [132].

It has been reported that Tat is also able to interact physically with C/EBP $\beta$ in vitro and in vivo [133]. Tat amino acid residues from 47 to 67 are critical for interaction with $\mathrm{C} / \mathrm{EBP} \beta$, and specifically Tat increases the distribution of nuclear levels of C/EBP $\beta$. Moreover, Tat can activate C/EBP $\beta$ in human U-373MG astroglial cells in a dose-dependent manner [134]. Recently, coexpression of Tat and C/EBP $\beta$ has been shown to enhance C/EBP $\beta$ binding to the HIV-1 LTR [135]. The N terminus of HIV-1 Tat (residues 1-26) has also been shown to bind to the transactivation domain (amino acids 1-96) within NFAT1 [136]. HIV-1 Tat enhances NFAT1-driven transcription in Jurkat $\mathrm{T}$ cells through a direct protein-protein interaction between the two proteins.

Tat is a robust transactivating protein that induces a number of effects by modulating the expression of many cellular and viral genes. Tat was recently shown to be associated with the promoters of PTEN and PP2A subunits, and these interactions result in activation of apoptotic pathways in HIV-1-infected CD4 ${ }^{+} \mathrm{T}$ cells [137]. These studies reinforce the fact that Tat, besides regulating the HIV-1 promoter, also affects cellular promoters. In addition to all of these interactions, Tat also interacts with a wide array of proteins, which have been summarized in Table 1. As shown here, there are a number of proteins with which Tat has been shown to interact. However, very little is known concerning a majority of these interactions and how they may or may not contribute to HIV-1 pathogenesis. This may be one reason why Tat inhibitors, discussed below, have universally failed to date to be effective in the therapeutic arena. In fact, given the large numbers of proteins already identified, future studies will undoubtedly need to take into account the interactome that Tat has with respect to the various proteins involved to truly begin to design inhibitors to attack these interactions. However, modeling this concept will be a future area that will need addressing.

\section{Molecular Diversity in Tat}

The high level of HIV sequence diversity generated during the course of HIV disease is, for the most part, due to the error-prone nature and low fidelity of reverse transcriptase, poor proofreading by the polymerase, and selective pressures exerted by the host immune response, combination antiretroviral chemotherapy, and perhaps other physiological pressures $[3,102,138]$. The HIV-1 genotypic variants and resultant phenotypes occur as important variables of viral replication during the course of the disease [139]. It has been reported that Tat can tolerate 38\% sequence variation without any change in its transactivation potential [140].
Both blood-derived and brain-derived HIV-1 viruses show immense molecular heterogeneity between patients and HIV-1 subtypes [53]. The LTR and several HIV-1 genes including [tat], [env] (gp120 and gp41), [nef], and [vpr] have been linked to the pathogenesis of HIV-related neurologic disease [141]. The molecular diversity of HIV-1 Tat protein isolated from brains of patients infected with different HIV-1 subtypes has been examined. Recent studies examining Tat proteins representative of HIV-1 subtype $\mathrm{B}, \mathrm{C}$, and $\mathrm{BF}$ recombinants have demonstrated important structural and functional differences [142, 143]. BF recombinant HIV-1 isolates from Argentina appear to have a replicative advantage over subtype B isolates, possibly due to the differential ability of Tat to interact with the LTR. Subtype C Tat has been shown to be more highly ordered than subtype B Tat. In addition, subtype C Tat protein has been demonstrated to be consistently inferior to subtype B Tat in biological assays with respect to its ability to promote viral proliferation, induce TNF- $\alpha$ and IL- 6 expression, and upregulate chemokine coreceptor expression [142]. However, studies have also shown that HIV-1 subtype C Tat exhibits greater transcriptional activity in the Jurkat CD4 ${ }^{+}$ $\mathrm{T}$ cell line compared with subtypes $\mathrm{B}$ and $\mathrm{E}$ and that this higher level of transactivation is not LTR sequence dependent but rather because of variations in the $\mathrm{C}$-Tat sequence at amino acid residues 57 ( $\mathrm{Arg}$ in $\mathrm{B}$ and $\mathrm{E}$, and Ser in $\mathrm{C}$ ) and 63 (Glu in B, E, and C), which are within and close to the basic domain, respectively [144]. In addition, in HIV-1 subtype $\mathrm{C}$ Tat, a serine residue replaces a cysteine at position 31. This variation affects the biological function of Tat, resulting in a deficient chemoattractant activity, low ability to bind to chemokine receptor 2 , and reduced ability to stimulate TNF- $\alpha$ production $[142,145,146]$ without affecting Tat transactivation. More recently, signature pattern analysis identified five amino acid positions in Tat $(21 \mathrm{~A}, 24 \mathrm{~N}$, $29 \mathrm{~K}, 40 \mathrm{~K}$, and $60 \mathrm{Q}$ ) that contained signature residues unique for Indian HIV-1C [147]. Interestingly in the eight patients analyzed to date in the DrexelMed HIV/AIDS Genetic Analysis Cohort [148], which contains mostly subtype Binfected patients, all of the Tat sequences analyzed contain these important cysteines (data not shown). Some length variation in exon 2 and the absence of a critical cysteine in the cysteine-rich domain have also been found in subtype $\mathrm{C}$ Tat [106]. When one compares the structural and functional differences between subtypes B and C Tat proteins [142], subtype $\mathrm{C}$ Tat may have a relatively higher ordered structure and be less flexible than subtype B Tat. Analysis of subtype $D$ Tat sequences revealed an in-frame stop codon in exon 2 , which results in removal of the 13-16 amino acids from the $C$ terminus of Tat $[103,149,150]$. Thus, emerging data encompassing the structure and function of the Tat protein across different subtypes have enabled us to better understand Tat-mediated effects. However, additional studies need to be performed to truly delineate the complexity of Tat. To accomplish this more sequencing data for all subtypes will have to be obtained to allow an even deeper understanding of how and why genetic variation evolves and what are the driving forces in this evolution especially on genes like tat that are not directly affected by antiretroviral therapy 
TABLE 1: List of all known Tat protein interactions and the nature of the functional activity compiled from PubMed (http://www.ncbi.nlm .nih.gov/pubmed/) and HIV-1, Human Protein Interaction Database (http://www.ncbi.nlm.nih.gov/RefSeq/HIVInteractions/).

\begin{tabular}{|c|c|}
\hline Human protein & Type of activity with Tat \\
\hline $2^{\prime}-5^{\prime}$-Oligoadenylate synthetase 2 isoform 1 & Interacts \\
\hline $2^{\prime}-5^{\prime}$-Oligoadenylate synthetase 3 & Interacts \\
\hline $2^{\prime}, 3^{\prime}$-Cyclic nucleotide $3^{\prime}$ phosphodiesterase & Activates \\
\hline $2^{\prime}, 5^{\prime}$-Oligoadenylate synthetase 1 isoform 2 & Interacts \\
\hline 8-Oxoguanine DNA glycosylase isoform 1a & Upregulates \\
\hline Actin, gamma 1 propeptide & Induces rearrangement of \\
\hline Activated RNA polymerase II transcription cofactor 4 & Binds \\
\hline Adaptor-related protein complex 2, alpha 1, 2 beta-1, mu-1, and sigma- 1 & Interacts \\
\hline Adenosine A2a receptor & Inhibited by \\
\hline Adenylate cyclase $2-9$ & Inhibits \\
\hline AFF4 & Involved in transcription \\
\hline Albumin precursor & Induces release \\
\hline Alpha 1 actin precursor & Induces rearrangement \\
\hline Alpha 1 type-I collagen preproprotein & Inhibits \\
\hline Alpha 2 actin & Induces rearrangement \\
\hline Alpha 2 type-I collagen & Inhibits \\
\hline Alpha isoform of regulatory subunit A, B55, protein phosphatase 2 & Modulated by \\
\hline Alpha-2-macroglobulin precursor & Inhibits \\
\hline AMP-activated protein kinase gamma 2 subunit isoform a & Activates \\
\hline AMP-activated protein kinase, noncatalytic gamma-1 subunit isoform 1 & Activates \\
\hline Amyloid beta A4 protein precursor, isoform a & Inhibits \\
\hline Annexin A2 isoform 2 & Downregulates \\
\hline Apolipoprotein E precursor & Inhibited by \\
\hline ATP-binding cassette subfamily B, C member 1 & Upregulates \\
\hline ATP-dependent DNA helicase II & Interacts \\
\hline ATP-dependent DNA helicase II, $70 \mathrm{kDa}$ subunit & Interacts \\
\hline Autoantigen La & Interacts \\
\hline B-cell CLL/lymphoma 11B isoform 1 & Binds \\
\hline B-cell lymphoma 6 protein & Upregulates \\
\hline B-cell lymphoma protein 2 alpha isoform & Interacts \\
\hline Baculoviral IAP repeat-containing protein 3 & Upregulates \\
\hline BCL2-antagonist of cell death protein & Induces phosphorylation \\
\hline BCL2-associated athanogene isoform 1L & Upregulates \\
\hline BCL2-associated X protein isoform beta & Interacts \\
\hline BCL2-like 1 isoform 1 & Upregulates \\
\hline BCL2-like 11 isoform 6 & Interacts \\
\hline Beta actin & Induces rearrangement \\
\hline Beta isoform of regulatory subunit A, B55 and B56, protein phosphatase 2 isoform a & Modulated by \\
\hline Beta tubulin 1 , class VI & Binds \\
\hline Beta-2-microglobulin precursor & Downregulates \\
\hline Bone-morphogenetic protein 1, 2 isoform 1, precursor & Upregulates \\
\hline Bone-morphogenetic protein receptor type-II precursor & Downregulates \\
\hline Brain adenylate cyclase 1 & Inhibits \\
\hline Breast cancer antiestrogen resistance 1 & Induces phosphorylation \\
\hline BTAF1 RNA polymerase II, B-TFIID transcription factor-associated, $170 \mathrm{kDa}$ & Interacts with \\
\hline c-Src tyrosine kinase & Activates \\
\hline Calcium/calmodulin-dependent protein kinase I & Downregulates \\
\hline Calcium/calmodulin-dependent protein kinase IIA, IIB isoform 1 & Inhibits \\
\hline cAMP-responsive element-binding protein 1 isoform A & Activates \\
\hline cAMP-responsive element modulator isoform v & Activates \\
\hline
\end{tabular}


Table 1: Continued.

\begin{tabular}{|c|c|}
\hline Human protein & Type of activity with Tat \\
\hline cAMP-dependent protein kinase catalytic subunit beta isoform 1 & Activates \\
\hline cAMP-dependent protein kinase, regulatory subunit alpha 1 and beta 2 & Activates \\
\hline cAMP-specific phosphodiesterase 4D & Activates \\
\hline Cardiac muscle alpha actin 1 proprotein & Induces rearrangement \\
\hline Caspase 3 preproprotein & Activates \\
\hline Caspase 8 isoform A precursor & Upregulates \\
\hline CC chemokine receptor 3 & Binds \\
\hline CCAAT/enhancer binding protein & Binds \\
\hline CCAAT/enhancer binding protein beta & Binds \\
\hline CD180 antigen & Downregulates \\
\hline CD28 antigen & Interacts \\
\hline CD3D antigen, delta polypeptide isoform A precursor & Interacts \\
\hline CD3E antigen, epsilon polypeptide (TiT3 complex) & Interacts \\
\hline CD3G gamma precursor & Interacts \\
\hline CD4 antigen precursor & Upregulates \\
\hline CD40 antigen isoform 1 precursor & Upregulates \\
\hline Cell division cycle 2 protein isoform 1 & Interacts \\
\hline Cell division cycle 20 and $25 \mathrm{C}$ protein & Downregulates \\
\hline Cell division cycle 37 protein & Regulated by \\
\hline Cell division cycle 6 protein & Interacts \\
\hline Chaperonin containing TCP1, subunit 4 (delta) & Interacts \\
\hline Chemokine (C motif) ligand 1, 3, 7 & Upregulates \\
\hline Chemokine (C-C motif) receptor 1 & Modulates \\
\hline Chemokine (C-C motif) receptor 2 isoform $\mathrm{B}$ & Binds \\
\hline Chemokine (C-C motif) receptor 4 & Upregulated by \\
\hline Chemokine (C-C motif) receptor 5 & Upregulates \\
\hline Chemokine (C-X-C motif) ligand 12 (stromal cell-derived factor 1 ) isoform beta & Interacts \\
\hline Chemokine (C-X-C motif) receptor 3 & Inhibits \\
\hline Chemokine (C-X-C motif) receptor 4 isoform b & Binds \\
\hline Chemokine (C-X3-C motif) ligand 1 & Inhibited by \\
\hline Chemokine $\mathrm{C}-\mathrm{C}$ motif ligand 4 isoform 1 precursor & Upregulates \\
\hline Chromobox homolog 5 (HP1 alpha homolog, Drosophila) & Inactivates \\
\hline Class II transactivator & Inhibits \\
\hline Claudin 1 & Downregulates \\
\hline Claudin 5 & Downregulates \\
\hline Cleavage and polyadenylation specific factor $3,73 \mathrm{kDa}$ & Upregulates \\
\hline Cofactor of BRCA1 & Associates with \\
\hline Cofilin 1 (nonmuscle) & Downregulates \\
\hline Cofilin 2 (muscle) & Downregulates \\
\hline Collagen, type-III, alpha 1 preproprotein & Upregulates \\
\hline Colony-stimulating factor 2 precursor & Upregulates \\
\hline Complement component 1 inhibitor precursor & Upregulates \\
\hline Complement component 1 , q subcomponent-binding protein precursor & Binds \\
\hline Core histone macro-H2A2.2 & Binds \\
\hline CREB-binding protein isoform a & Binds \\
\hline CREB3: cAMP-responsive element binding protein 3 (luman) & Inhibited by \\
\hline CTD (carboxy-terminal domain, RNA polymerase II, polypeptide A) phosphatase, subunit 1 isoform FCP1a & Binds \\
\hline CXCL16 & Interacts \\
\hline Cyclin A, A1, E1 & Interacts \\
\hline Cyclin B1 & Upregulates \\
\hline Cyclin $\mathrm{C}$ isoform a & Interacts \\
\hline Cyclin D1 & Downregulates \\
\hline
\end{tabular}


Table 1: Continued.

\begin{tabular}{|c|c|}
\hline Human protein & Type of activity with Tat \\
\hline Cyclin D3 & Interacts \\
\hline Cyclin $\mathrm{H}$ & Binds \\
\hline Cyclin T1 & Binds \\
\hline Cyclin T2 isoform a & Binds \\
\hline Cyclin-dependent kinase 2 isoform 1 & Enhances \\
\hline Cyclin-dependent kinase 4 & Interacts \\
\hline Cyclin-dependent kinase 5 & Downregulates \\
\hline Cyclin-dependent kinase 7 & Binds \\
\hline Cyclin-dependent kinase 8 & Interacts \\
\hline Cyclin-dependent kinase 9 & Binds \\
\hline Cyclin-dependent kinase inhibitor $1 \mathrm{~A}$ & Activates \\
\hline Cyclin-dependent kinase inhibitor 1B & Interacts \\
\hline Cytochrome c & Induces release of \\
\hline Cytoplasmic nuclear factor of activated T cells 3 isoform 1 & Activates \\
\hline Cytoplasmic nuclear factor of activated T cells 4 & Activates \\
\hline Delta isoform of regulatory subunit $\mathrm{B} 56$, protein phosphatase $2 \mathrm{~A}$ isoform 1 & Modulated by \\
\hline Dicer1 & Interacts \\
\hline Dipeptidyl peptidase IV & Inhibits \\
\hline Diubiquitin & Ubiquitinated by \\
\hline DNA-dependent protein kinase & Modulates HIV gene expression \\
\hline DNA-directed RNA polymerase II polypeptides & Interacts \\
\hline DNA polymerase epsilon catalytic subunit & Interacts \\
\hline DNA-damage-inducible transcript 3 & Enhanced by \\
\hline DNA-directed RNA polymerase III $39 \mathrm{kDa}$ polypeptide $\mathrm{F}$ & Activates \\
\hline Dopamine transporter & Inhibits \\
\hline Downregulator of transcription 1 & Inhibits \\
\hline E1A-binding protein p300 & Complexes with \\
\hline E2F transcription factor 1 & Inhibited by \\
\hline E2F transcription factor 4 & Recruits \\
\hline Early growth response $1,2,3$ & Binds \\
\hline Egr-1 in astrocytes & Tat-mediated toxicity in astrocytes \\
\hline Elongation factor RNA polymerase II & Interacts \\
\hline Elongin B isoform a & Interacts \\
\hline Endonuclease G precursor & Activates \\
\hline Endothelial differentiation-related factor 1 isoform alpha & Downregulates \\
\hline Endothelin 1 & Upregulates \\
\hline Enolase 1 & Inhibits \\
\hline EP300 & Binds \\
\hline Epidermal growth factor (beta urogastrone) & Interacts \\
\hline Epsilon isoform of regulatory subunit B56, protein phosphatase $2 \mathrm{~A}$ & Modulated by \\
\hline Eukaryotic translation elongation factor 1 alpha 1,2 & Interacts \\
\hline Eukaryotic translation initiation factor 2-alpha kinase 2 & Interacts \\
\hline Excision repair cross-complementing rodent repair deficiency, complementation group 2 protein & Binds \\
\hline Excision repair cross-complementing rodent repair deficiency, complementation group 3 & Binds \\
\hline Fas ligand & Interacts \\
\hline Fc fragment of IgG, low affinity IIIa, receptor for (CD16) & Inhibits \\
\hline Fibroblast growth factor 1 (acidic) isoform 1 precursor & Upregulates \\
\hline Fibronectin 1 isoform 3 preproprotein & Competes with \\
\hline \multicolumn{2}{|c|}{ Fms-related tyrosine kinase 1 (vascular endothelial growth factor/vascular permeability factor receptor) Binds } \\
\hline Furin preproprotein & Cleaved by \\
\hline Galectin 3 & Upregulates \\
\hline Gamma isoform of regulatory subunit B55, protein phosphatase 2 isoform a & Regulated by \\
\hline
\end{tabular}


Table 1: Continued.

\begin{tabular}{|c|c|}
\hline Human protein & Type of activity with Tat \\
\hline Gastrointestinal glutathione peroxidase 2 & Modulates \\
\hline GATA-binding protein 2 & Synergizes with \\
\hline GCN5 general control of amino-acid synthesis 5 -like 2 & Binds \\
\hline Gelsolin isoform a precursor & Downregulates \\
\hline General transcription factor iib, $\mathrm{e}, \mathrm{f}$, and $\mathrm{h}$ & Interacts \\
\hline General transcription factor IIIC, polypeptide 1 , alpha $220 \mathrm{kDa}$ & Activates \\
\hline GLI-Kruppel family member GLI2 & Synergizes with \\
\hline Glial fibrillary acidic protein & Upregulates \\
\hline Glucocerebrosidase precursor & Interacts \\
\hline Glucose-6-phosphate dehydrogenase isoform a & Activates \\
\hline Glutamate receptor, ionotropic, N-methyl-D-aspartate 3A, 3B & Activates \\
\hline Glutamate receptor, metabotropic 1 & Activates \\
\hline Glutathione peroxidase 1 isoform $1,4,5,6,7$ & Downregulates \\
\hline Glutathione synthetase & Modulates \\
\hline Glycogen synthase kinase 3 beta & Activates \\
\hline Glycophorin A precursor & Downregulates \\
\hline Granulin precursor & Binds \\
\hline Grb2 & Binds through SH3 domains \\
\hline Growth factor receptor-bound protein 2 isoform 1 & Recruits \\
\hline Growth hormone 1 isoform 1 & Inhibited by \\
\hline H2A histone family members & Binds \\
\hline $\mathrm{H} 2 \mathrm{~B}$ histone family members & Binds \\
\hline H3 histone family members & Binds \\
\hline H4 histone family members & Binds \\
\hline Heat shock $70 \mathrm{kDa}$ proteins & Regulated by \\
\hline Heparan sulfate proteoglycan 2 & Interacts \\
\hline Heparanase & Interacts \\
\hline Hexamethylene bis-acetamide inducible 1,2 & Inhibited by \\
\hline Histone 1, h2ad & Binds \\
\hline Histone 2, H4 & Binds \\
\hline Histone deacetylase 1 & Inhibited by \\
\hline Histone h2a & Binds \\
\hline Histone $\mathrm{H} 2 \mathrm{~A}$ & Binds \\
\hline Histone H2B & Binds \\
\hline Histone H4 & Binds \\
\hline HIV TAT specific factor 1 & Stimulated by \\
\hline HIV-1 Tat interactive protein 2, $30 \mathrm{kDa}$ & Stimulates \\
\hline HIV-1 Tat interactive protein, $60 \mathrm{kDa}$ isoform 1 & Binds \\
\hline HMT1 hnRNP methyltransferase-like 6 & Methylated by \\
\hline Human immunodeficiency virus type-I enhancer binding protein 1 & Enhanced by \\
\hline Inhibitor of DNA-binding 1 isoform a & Upregulates \\
\hline Inil/hSNF5 & Interacts \\
\hline Inositol 1,4,5-triphosphate receptor, type 1, 2, 3 & Interacts \\
\hline Insulin-like growth factor 1 (somatomedin C) & Inhibited by \\
\hline Insulin-like growth factor-binding protein 4 precursor & Binds \\
\hline Integrin alpha 3 isoform a precursor & Activates \\
\hline Integrin alpha 5 precursor & Binds \\
\hline Integrin alpha L precursor & Inhibits \\
\hline Integrin beta 1 isoform $1 \mathrm{~A}$ precursor & Interacts \\
\hline Integrin beta 4 isoform 1 precursor & Interacts \\
\hline Integrin beta chain, beta 3 precursor & Interacts \\
\hline Integrin, beta 2 precursor & Inhibits \\
\hline
\end{tabular}


Table 1: Continued.

\begin{tabular}{|c|c|}
\hline Human protein & Type of activity with Tat \\
\hline Integrin, beta 5 & Interacts \\
\hline Intercellular adhesion molecule 1 precursor & Interacts \\
\hline Interferon regulatory factor 1 & Binds \\
\hline Interferon regulatory factor 7 isoform a & Upregulates \\
\hline Interferon-stimulated gene $20 \mathrm{kDa}$ & Upregulates \\
\hline Interferon-induced protein 35 & Upregulates \\
\hline Interferon-induced protein with tetratricopeptide repeats 3 & Upregulates \\
\hline Interferon-induced, hepatitis $\mathrm{C}$-associated microtubular aggregate protein & Upregulates \\
\hline Interferon, alpha 1 & Interacts \\
\hline Interferon, alpha-inducible protein (clone IFI-15 K) & Upregulates \\
\hline Interferon, alpha-inducible protein 27 & Upregulates \\
\hline Interferon, beta 1 , fibroblast & Interacts \\
\hline Interferon, gamma & Inhibited by \\
\hline Interferon, gamma-inducible protein 16 & Upregulates \\
\hline Interleukin 1 receptor antagonist isoform 2 & Upregulates \\
\hline Interleukin 1 receptor, type I precursor & Upregulates \\
\hline Interleukin 1, alpha proprotein & Downregulates \\
\hline Interleukin 1 , beta proprotein & Downregulates \\
\hline Interleukin 10 precursor & Inhibited by \\
\hline Interleukin $12 \mathrm{~A}$ precursor & Downregulates \\
\hline Interleukin $12 \mathrm{~B}$ precursor & Downregulates \\
\hline Interleukin 13 precursor & Induces release of \\
\hline Interleukin 16 isoform 1 precursor & Inhibited by \\
\hline Interleukin 19 isoform 1 precursor & Upregulates \\
\hline Interleukin 2 precursor & Downregulates \\
\hline Interleukin 2 receptor beta precursor & Downregulates \\
\hline Interleukin 2 receptor, alpha chain precursor & Upregulates \\
\hline Interleukin 20 precursor & Upregulates \\
\hline Interleukin 3 precursor & Upregulates \\
\hline Interleukin 4 isoform 1 precursor & Interacts \\
\hline Interleukin 6 (interferon, beta 2) & Activated by \\
\hline Interleukin 6 receptor isoform 1 precursor & Upregulates \\
\hline Interleukin 7 precursor & Inhibits \\
\hline Interleukin 7 receptor precursor & Inhibits \\
\hline Interleukin 8 precursor & Downregulates \\
\hline Jun oncogene & Binds \\
\hline Karyopherin beta 1 & Binds \\
\hline Kinase insert domain receptor (a type-III receptor tyrosine kinase) & Interacts with \\
\hline Kinesin family member $2 \mathrm{C}$ & Downregulates \\
\hline Kruppel-like factor 9 & Enhanced by \\
\hline Lactate dehydrogenase A & Downregulates \\
\hline Lactate dehydrogenase B & Downregulates \\
\hline Lamin $\mathrm{A} / \mathrm{C}$ isoform 1 precursor & Binds \\
\hline Lamin B1 & Binds \\
\hline Lamin B2 & Binds \\
\hline Laminin alpha 5 & Upregulates \\
\hline Laminin subunit beta 3 precursor & Upregulates \\
\hline Laminin, alpha 1 precursor & Upregulates \\
\hline Laminin, alpha 4 precursor & Upregulates \\
\hline Laminin, beta 1 precursor & Upregulates \\
\hline Laminin, beta 2 precursor & Upregulates \\
\hline Laminin, beta 4 & Upregulates \\
\hline
\end{tabular}


Table 1: Continued.

\begin{tabular}{|c|c|}
\hline Human protein & Type of activity with Tat \\
\hline Laminin, gamma 1 precursor & Upregulates \\
\hline Laminin, gamma 2 isoform a precursor & Upregulates \\
\hline Laminin, gamma 3 precursor & Upregulates \\
\hline Low affinity immunoglobulin gamma Fc region receptor III-B precursor & Inhibits \\
\hline Low-density lipoprotein-related protein 1 & Binds \\
\hline LSD1/KDM1 & Modulates transcription \\
\hline Lymphocyte-specific protein tyrosine kinase precursor & Activates \\
\hline Lymphotoxin alpha precursor & Upregulates \\
\hline MAD, mothers against decapentaplegic homolog 6 & Downregulates \\
\hline Major histocompatibility complex, class I & Downregulates \\
\hline Major histocompatibility complex, class II & Downregulates \\
\hline Manganese superoxide dismutase isoform A precursor & Downregulates \\
\hline Mannose receptor C type-1 precursor & Downregulates \\
\hline Mannose receptor C type 2 & Downregulates \\
\hline Matrix metalloproteinase & Activates \\
\hline Menage a trois 1 (CAK assembly factor) & Binds \\
\hline Metallothioneins & Upregulates \\
\hline Methyltransferase-like protein 1 isoform a & Downregulates \\
\hline Microtubule-associated deacetylase HDAC6 & Tat acetylation and transactivation \\
\hline Mitogen-activated protein kinases & Activates \\
\hline Mothers against decapentaplegic homolog 3 & Inhibited by \\
\hline Mothers against decapentaplegic homolog 4 & Inhibited by \\
\hline Mouse double minute 2 homolog isoform MDM2 & Regulated by \\
\hline Myc protooncogene protein & Upregulates \\
\hline MyoD family inhibitor domain containing isoform p40 & Binds \\
\hline Myxovirus resistance protein 1 & Upregulates \\
\hline Nasal embryonic LHRH factor & Associates with \\
\hline Nerve growth factor, beta polypeptide precursor & Inhibits \\
\hline Neutrophil cytosolic factor 1 & Interacts \\
\hline Nitric oxide synthase $2 \mathrm{~A}$ isoform 1 & Inhibits \\
\hline Nitric oxide synthase 3 (endothelial cell) & Upregulates \\
\hline NMDA receptor 1 isoforms & Activates \\
\hline Notch 2 preproprotein & Interacts \\
\hline Nrf2 transcription factor & Fusion to Tat \\
\hline Nuclear factor I/C isoform 1 & Synergizes with \\
\hline Nuclear factor kappa-B, subunit 1 & Interacts \\
\hline Nuclear factor of activated T cells, cytosolic component 1 isoform A & Activates \\
\hline Nuclear factor of activated T cells, cytoplasmic, calcineurin-dependent 2 isoform B & Binds \\
\hline Nuclear factor of kappa light polypeptide gene enhancer in B cells & Activates \\
\hline Nuclear receptor coactivator 1 isoform 1 & Stimulates \\
\hline Nuclear receptor coactivator 2 & Stimulates \\
\hline Nuclear receptor coactivator 3 isoform a & Enhanced by \\
\hline Nuclear receptor subfamily 2 , group F, member 1 & Interacts \\
\hline Nuclease-sensitive element binding protein 1 & Binds \\
\hline Nucleophosmin 1 isoform 1 & Binds \\
\hline Nucleosome assembly protein 1 & Interacts \\
\hline $\mathrm{P}-\mathrm{TEFb}$ & Binds \\
\hline p21-activated kinase 1 & Interacts \\
\hline p300/CBP-associated factor & Interacts \\
\hline p65 - n & Binds \\
\hline Paired mesoderm homeobox 1 isoform pmx-la & Downregulates \\
\hline Pancreas-enriched phospholipase C & Activates \\
\hline
\end{tabular}


Table 1: Continued.

\begin{tabular}{|c|c|}
\hline Human protein & Type of activity with Tat \\
\hline Paxillin & Induces phosphorylation of \\
\hline Phorbolin 1 & Upregulates \\
\hline Phosphatase and tensin homolog & Downregulates \\
\hline Phosphodiesterases & Activates \\
\hline Phosphoinositide-3-kinases & Interacts with \\
\hline Phosphoinositide-specific phospholipase $\mathrm{C}$ beta 1 isoform a & Activates \\
\hline Phospholipase C isoforms & Activates \\
\hline Plasma glutathione peroxidase 3 precursor & Downregulates \\
\hline Plasminogen activator inhibitor-1 & Modulates \\
\hline Platelet-activating factor acetylhydrolase, isoform Ib, alpha subunit ( $45 \mathrm{kDa})$ & Interacts \\
\hline Poly(ADP-ribose) polymerase family, member 1 & Regulates \\
\hline $\operatorname{Poly}(\mathrm{A})$ polymerase alpha & Regulates \\
\hline Poly(A) polymerase beta (testis specific) & Regulates \\
\hline Poly(A) polymerase gamma & Regulates \\
\hline Polymerase (DNA directed), beta & Upregulates \\
\hline Polymerase (RNA) III (DNA directed) polypeptides & Activates \\
\hline Polypyrimidine tract-binding protein 2 & Interacts \\
\hline Polypyrimidine tract-binding protein 1 isoform a & Interacts \\
\hline POU domain, class 2, transcription factor 1 & Binds \\
\hline PRF1: perforin 1 (pore forming protein) & Downregulates \\
\hline Prion protein preproprotein & Upregulates \\
\hline PRKC, apoptosis, WT1, regulator & Upregulates \\
\hline Programmed cell death 11 & Modulated by \\
\hline Proliferating cell nuclear antigen & Interacts \\
\hline Promyelocytic leukemia protein isoform 1 & Regulated by \\
\hline Prostaglandin-endoperoxide synthase 2 precursor & Upregulates \\
\hline Proteasome (prosome, macropain) 26S subunit, non-ATPase, 6 & Interacts \\
\hline Proteasome (prosome, macropain) activator subunit 4 & Interacts \\
\hline Proteasome 26S ATPase subunits & Interacts \\
\hline Proteasome $26 \mathrm{~S}$ non-ATPase subunits & Interacts \\
\hline Proteasome activator subunits & Interacts \\
\hline Proteasome alpha subunits & Interacts \\
\hline Proteasome beta subunits & Interacts \\
\hline Proteasome inhibitor subunit 1 isoform 1 & Interacts \\
\hline Protein kinase $\mathrm{C}$ & Activates \\
\hline Protein kinase D & Regulated by \\
\hline Protein kinase, camp dependent & Activates \\
\hline Protein kinase, DNA-activated, catalytic polypeptide & Binds \\
\hline Protein phosphatase 1 & Through Cdk9 phosphorylation \\
\hline Protein phosphatase 1 regulatory inhibitor subunit 8 isoform alpha & Binds \\
\hline Protein phosphatase 1 , catalytic subunits & Binds \\
\hline Protein phosphatase 2, catalytic subunits & Modulated by \\
\hline Protein phosphatase 3 , catalytic subunits & Activates \\
\hline Protein tyrosine phosphatase, nonreceptor type 23 & Upregulates \\
\hline Protooncogene tyrosine-protein kinase SRC & Activates \\
\hline PTK2 protein tyrosine kinase 2 isoform a & Activates \\
\hline PTK2B protein tyrosine kinase 2 beta isoform a & Induces phosphorylation \\
\hline Purine-rich element-binding protein A & Binds \\
\hline RAD51 homolog protein isoform 1 & Interacts \\
\hline RAN-binding protein 5 & Binds \\
\hline Ras homolog gene family, member A & Activates \\
\hline Ras-related C3 botulinum toxin substrate 1 isoform Rac1 & Activates \\
\hline
\end{tabular}


Table 1: Continued.

\begin{tabular}{|c|c|}
\hline Human protein & Type of activity with Tat \\
\hline Ras-related C3 botulinum toxin substrate 2 & Activates \\
\hline RD RNA-binding protein & Associates \\
\hline RelB & Through inhibition of $\operatorname{tnf} \alpha$ \\
\hline Replication factor C2 (40 kDa) isoform 1 & Interacts \\
\hline Replication factor C3 isoform 1 & Interacts \\
\hline Replication factor $\mathrm{C} 4$ & Interacts \\
\hline Replication factor C5 isoform 1 & Interacts \\
\hline Replication factor C large subunit & Interacts \\
\hline Replication protein $\mathrm{A} 1,70 \mathrm{kDa}$ & Interacts \\
\hline Reticuloendotheliosis viral oncogene homolog B & Interacts \\
\hline Retinoblastoma 1 & Inhibited by \\
\hline Retinoblastoma-like 2 (p130) & Binds \\
\hline Rho GDP dissociation inhibitor (GDI) alpha & Downregulates \\
\hline Ribosomal protein L3 isoform a & Interacts \\
\hline RNA guanylyltransferase and $5^{\prime}$-phosphatase & Binds \\
\hline RNA polymerase II, polypeptide $\mathrm{H}$ & Activates \\
\hline S-phase kinase-associated protein 2 isoform 1 & Enhanced by \\
\hline Secretoglobin, family $2 \mathrm{~A}$, member 2 & Upregulates \\
\hline Selectin E precursor & Upregulates \\
\hline Semaphorin $4 \mathrm{D}$ & Upregulates \\
\hline SHC (Src homology 2 domain containing) transforming protein 1 isoform p52Shc & Induces phosphorylation of \\
\hline Signal transducer and activator of transcription 1 isoform alpha & Upregulates \\
\hline Signal transducer and activator of transcription 3 isoform 2 & Activates \\
\hline Signal transducer and activator of transcription 6 & Interacts \\
\hline Single-stranded DNA-binding protein 1 & Upregulates \\
\hline Sirtuin 1 & Regulated by \\
\hline SKI-interacting protein & Associates \\
\hline SKIP & Interacts through c-Myc and Menin \\
\hline Small GTPase protein E-Ras & Activates \\
\hline Small inducible cytokine precursors & Inhibits \\
\hline Small inducible cytokine subfamily E, member 1 & Upregulates \\
\hline Small nuclear ribonucleoprotein polypeptide & Stimulated by \\
\hline Solute carrier family 22 , member 1 isoform a & Regulated by \\
\hline Solute carrier family 5 (sodium/glucose cotransporter), member 1 & Inhibits \\
\hline Solute carrier family 6 (neurotransmitter transporter, dopamine), member 3 & Downregulates \\
\hline Sp1 transcription factor & Interacts \\
\hline SP110 nuclear body protein isoform a & Upregulates \\
\hline Sp3 transcription factor isoform 1 & Interacts \\
\hline Sp4 transcription factor & Interacts \\
\hline Spermidine/spermine N1 acetyltransferase & Upregulates \\
\hline Splicing factor, arginine/serine-rich 1 isoform 1 & Inhibits \\
\hline Splicing factor, arginine/serine-rich 7 & Inhibits \\
\hline Squamous cell carcinoma antigen recognized by T cells 3 & Regulated by \\
\hline SRB7 suppressor of RNA polymerase B homolog & Interacts \\
\hline Src homology 2 domain containing transforming protein C3 & Induces phosphorylation \\
\hline Succinate dehydrogenase complex, subunit B, iron sulfur (Ip) & Binds \\
\hline Superoxide dismutase 1 , soluble & Downregulates \\
\hline Superoxide dismutase 3, extracellular precursor & Downregulates \\
\hline Suppressor of Ty 4 homolog 1 & Activated by \\
\hline Suppressor of Ty 5 homolog & Stimulated by \\
\hline SWI/SNF-related, matrix-associated, and actin-dependent regulator of chromatin & Binds \\
\hline Syndecan $1-4$ precursors & Binds \\
\hline
\end{tabular}


Table 1: Continued.

\begin{tabular}{|c|c|}
\hline Human protein & Type of activity with Tat \\
\hline T-box 21 & Upregulates \\
\hline T-cell receptor zeta chain isoform 1 precursor & Interacts \\
\hline TAF12 RNA polymerase II, TATA box-binding protein (TBP)-associated factor, $20 \mathrm{kDa}$ & Interacts \\
\hline TAF9 RNA polymerase II isoform a & Interacts \\
\hline TAR DNA-binding protein & Inhibited by \\
\hline TAR RNA-binding protein 1 & Regulates \\
\hline TAR RNA-binding protein 2 isoform a & Synergizes \\
\hline TAT-interactive protein, $72 \mathrm{kDa}$ & Binds \\
\hline TATA box-binding protein & Interacts \\
\hline TATA box-binding protein-associated factor $2 \mathrm{~F}$ & Interacts \\
\hline TBP-1 interacting protein isoform 2 & Inhibited by \\
\hline TBP-associated factors & Interacts \\
\hline Telomerase reverse transcriptase isoform 1 & Downregulates \\
\hline Testis-specific histone $\mathrm{H} 2 \mathrm{~B}$ & Binds \\
\hline TFIIA alpha, p55 isoform 1 & Stabilizes \\
\hline TH1-like protein & Associates \\
\hline Thrombospondin 1 precursor & Binds \\
\hline Thyroid hormone receptor, alpha isoform 2 & Binds \\
\hline Tight junction protein 2 (zona occludens 2 ) isoform 1 & Downregulates \\
\hline Tissue inhibitor of metalloproteinase 1 precursor & Interacts \\
\hline Tissue inhibitor of metalloproteinase 2 precursor & Interacts \\
\hline TNF receptor-associated factor 4 & Inhibited by \\
\hline Transcription elongation factor A (SII), 3 & Interacts \\
\hline Transcription elongation factor A1 isoform 1 & Interacts \\
\hline Transcription elongation factor A protein 2 isoform a & Interacts \\
\hline Transcription elongation regulator 1 isoform 1 & Associates with \\
\hline Transcription factor 3 & Regulated by \\
\hline Transcription factor 4 isoform $b$ & Inhibits \\
\hline Transcription factor 7-like 2 (T-cell specific, HMG-box) & Regulated by \\
\hline Transcription factor AP-4 (activating enhancer binding protein 4) & Regulated by \\
\hline Transcription factor $\mathrm{CP} 2$ & Inhibited by \\
\hline Transforming growth factor, alpha & Upregulates \\
\hline Transforming growth factor, beta 1 & Inhibited by \\
\hline Transforming growth factor, beta 2 & Upregulates \\
\hline Transporter 1, ATP-binding cassette, subfamily B & Upregulates \\
\hline Transportin 1 & Binds \\
\hline Tripartite motif-containing 22 & Inhibited by \\
\hline TUBB4Q: tubulin, beta polypeptide 4 , member Q & Downregulates \\
\hline Tubulin alpha 6 & Binds \\
\hline Tubulin, alpha 1 & Binds \\
\hline Tubulin, alpha 1a & Binds \\
\hline Tubulin, alpha 2 isoform 1 & Binds \\
\hline Tubulin, alpha 4 & Binds \\
\hline Tubulin, alpha 8 & Binds \\
\hline Tubulin, alpha, ubiquitous & Binds \\
\hline Tubulin, beta & Downregulates \\
\hline Tubulin, beta 2 & Binds \\
\hline Tubulin, beta $2 \mathrm{~B}$ & Downregulates \\
\hline Tubulin, beta 4 & Binds \\
\hline Tubulin, beta 6 & Binds \\
\hline Tubulin, beta 8 & Binds \\
\hline
\end{tabular}


Table 1: Continued.

\begin{tabular}{|c|c|}
\hline Human protein & Type of activity with Tat \\
\hline Tubulin, beta, 2 & Binds \\
\hline Tubulin, beta, 4 & Binds \\
\hline Tumor necrosis factor (ligand) superfamily, member 10 & Inhibits \\
\hline Tumor necrosis factor alpha & Interacts \\
\hline Tumor necrosis factor receptors & Upregulates \\
\hline Tumor protein p53 & Binds \\
\hline Tumor protein $\mathrm{p} 73$ & Binds \\
\hline Tyrosine hydroxylase isoform b & Downregulates \\
\hline Ubiquitin B precursor & Ubiquitinated by \\
\hline Ubiquitin $\mathrm{C}$ & Ubiquitinated by \\
\hline Ubiquitin-activating enzyme E1 & Ubiquitinated by \\
\hline Ubiquitin-conjugating enzyme E2D 1 & Ubiquitinated by \\
\hline Upstream-binding protein 1 (LBP-1a) & Inhibits \\
\hline Urokinase plasminogen activator preproprotein & Upregulates \\
\hline V-akt murine thymoma viral oncogene homolog 2 & Activates \\
\hline V-akt murine thymoma viral oncogene homolog 3 isoform 1 & Activates \\
\hline V-fos FBJ murine osteosarcoma viral oncogene homolog & Interacts \\
\hline V-Ha-ras Harvey rat sarcoma viral oncogene homolog isofrom 1 & Activates \\
\hline V-rel reticuloendotheliosis viral oncogene homolog & Interacts \\
\hline Vascular cell adhesion molecule 1 isoform a precursor & Upregulates \\
\hline Vascular endothelial growth factor A isoform b precursor & Cooperates with \\
\hline Vitronectin precursor & Competes with \\
\hline Wolf-Hirschhorn syndrome candidate 2 protein & Downregulates \\
\hline YY1 transcription factor & Inhibited by \\
\hline Zinc finger and BTB domain containing 7A & Binds \\
\hline
\end{tabular}

and therefore have direct selective pressures. The power of having large data sets can be demonstrated in a recent study which has identified two residues in Tat, positions 35 and 39, which appear to be coevolved. These residues, however, have two distinct functions with respect to the transactivation of the HIV-1 LTR-binding P-TEFb and promoting P-TEFb phosphorylation of the C-terminal domain in RNAPII, respectively [151]. In addition, understanding the genetic diversity of Tat in multiple subtypes has become and will continue to be increasingly important as vaccines in development will need to account for immunity to all of these variations.

\section{Tat Genetic Variation and HIV-1-Associated Neurological Disorders}

In addition to transactivation of the viral LTR, Tat exhibits a range of biological properties relative to HIV-1 pathogenesis [152], including the intracellular regulation of host gene expression to facilitate viral production as well as the extracellular detrimental effects on the cells of the immune and nervous systems. HIV-1 induces pathological consequences in a number of end organs including the brain [7, 153]. More than $30 \%$ of AIDS patients suffer from some form of HIV-1-induced neurological impairment including HIV1-associated dementia (HAD) as well as other more subtle minor neurocognitive disorders $[154,155]$. Despite the widespread use of highly active antiretroviral therapy and the resultant decrease in the incidence of $\mathrm{HAD}$, the prevalence of HAD and other milder forms of HIV-related neurological disease has become increasingly common problems with respect to the clinical management of HIV/AIDS [156]. In particular, Tat has been implicated in the pathogenesis of HIV-associated neurological disease including HAD via a variety of mechanisms [157]. The neurotoxicity of Tat is further supported by the observation that the mRNA levels for Tat are elevated in brain extracts of patients with HAD [158]. Tat has been shown to act as an intracellular and extracellular mediator of neurotoxicity and to play a critical role in contributing to neurological injury in HAD [159]. Tat protein is secreted by HIV-1-infected cells and acts by diffusing through the cell membrane. It appears to act as a secreted, soluble neurotoxin and induces HIV-1infected macrophages and microglia to release neurotoxic substances [160-162]. Some Tat variants have been reported to be dysfunctional with respect to LTR transactivation and may contribute to viral latency under certain conditions while still being able to stimulate the transcription of a number of cytokine genes [95]. Tat can also cooperate with cellular factors to enhance the neurotoxic effects on host cells [163]. Tat and cytokines IFN- $\gamma$ and TNF- $\alpha$ have also been demonstrated to synergistically increase expression of CXCL10 in human astrocytes, which provide an important 
reservoir for the generation of inflammatory mediators, for instance, CXCL10 as a neurotoxin and a chemoattractant [164].

Phylogenetic analyses of Tat sequences from patients with and without HAD have shown clustering of sequences with respect to clinical diagnosis of neurological impairment as well as tissue of origin $[165,166]$. Comparisons of matched brain and spleen-derived Tat sequences have suggested that greater sequence homology exists among brain-derived Tat clones than that observed between brain and spleen-derived clones [166]. Another study also showed sequence variations within patients segregated as CNS and non-CNS tat genes [167]. Additionally, significant sequence heterogeneity exists within brain-derived Tat in domains associated with viral replication and intracellular transport [166]. Nonsynonymous versus synonymous mutation rates among brainderived Tat sequences isolated from patients with neurocognitive impairment were shown to be significantly greater than those isolated from patients without clinical evidence of neurological disease [165]. Importantly, most of the mutations present in the HAD-associated Tat sequences were located in the augmenting region (residues 57-78 amino acids), which affects viral replication. Interestingly, in these studies, variations at position 74 and 100 were correlated to Tat sequences isolated from brain-derived sequences. Collectively, results from these studies suggest that differing selective pressures act on individual HIV-1 genes within the CNS and that this differential selective pressure may influence both the development and subsequent severity of neurocognitive impairment.

Participants in a current longitudinal study of patients in the DrexelMed HIV/AIDS Genetic Analysis Cohort have had their LTR and their env and tat genes and proteins, where appropriate, analyzed from peripehral blood. The LTR was analyzed as a result of previous studies that identified the potential for single nucleotide polymorphisms in the LTR to be predictive of neurocognitive impairment [168170]. Patients within the DrexelMed HIV/AIDS Genetic Analysis Cohort are followed longitudinally, with scheduled visits every 6 months. At each visit, patients are interviewed for clinical and social history, a blood sample is collected, and neurocognitive status is evaluated with a minineurological exam [171]. Recently, eight patients were analyzed with respect to Tat genetic variation. Longitudinal analyses of these 8 patients showed 7 of the patients had exhibited NI at some point in their clinical history; of these 7 patients, 3 patients had current NI and all 3 had Tat containing a change at amino acid position 100 (amino acid 100). Of the remaining 4 patients, 2 had the change at amino acid 100 with their following visit showing NI; the final 2 did not have a change at amino acid 100; however, these patients were lost to follow up for 23-36 months, at which time they presented with NI. The one patient without NI did not have a change at amino acid 100. Given the previous studies, which have identified this amino acid position as indicative of brainderived sequences, this observation may point to the fact that a change at this amino acid position may occur in the periphery in patients before the onset of NI (perhaps in the HIV-1-infected monocyte-macrophage compartment).
The genetic variation observed within Tat has also been shown to alter the function of this protein and relate to pathogenesis. Importantly, HIV-1 Tat derived from HAD patients has been associated with greater neuronal death both in vitro and in vivo compared with Tat from non-HAD patients. This characteristic has been attributed, in part, to enhanced MMP-2 expression induced by brain-derived HIV-1 Tat variants [172]. Interestingly, however, these same brain-derived Tat isolates also appear to be limited in their ability to enhance viral gene expression despite the increased activation of host transcriptional machinery [173]. This observation differs from other reported studies, which showed that a subset of patients demonstrated reduced transactivation capacity of CNS-derived Tat proteins compared to those from matched lymphoid tissues; however, overall Tat proteins from the CNS, when compared to lymphoid compartments, maintained similar levels of transactivation function [167]. However, one must remember that these viral gene activation studies were all performed with a viral regulatory region derived from a non-CNS tissue source and may therefore not be naturally compatible with respect to optimal LTR activation by a Tat protein selected for CNS replication. This observation is of particular importance because previous studies [168, 174, 175] have demonstrated that LTRs derived from the CNS are likely to be structurally and functionally different from LTRs derived from other tissue sources. In fact, a current study has shown that Tat transactivates the corresponding HIV1-infected patient-derived colinear LTR better than a nonco-linear Tat protein. These Tat clones were shown to have nonconsensus variations compared with IIIB or the consensus B sequence of Tat that might contribute to the alteration in their function [171]. Taken together, these reports point to the notion that genetic diversity of HIV-1 Tat likely contributes to the establishment and severity of HIV-1-associated neurological disease. However, additional studies of this nature are warranted. For instance, are there certain Tat residues that induce increased Tat secretion from cells both in the periphery as well as in the CNS? Are there variations that induce more neurotoxic effects? Are the Tat variants isolated from vRNA versus integrated DNA similar or different?

\section{HIV-1 Tat as a Therapeutic Target}

The HIV-1 Tat protein has long remained an attractive target for therapeutic intervention owing to its essential role in viral gene expression and activation of the HIV-1 LTR. As discussed before, Tat and the P-TEFb complex bind to TAR to promote efficient transcription of the full-length HIV genome. The expanding knowledge of Tat functional properties and its interactions with other cellular and viral partners has led to the identification of a varied range of compounds that can inhibit different Tat functions. The Tat and HIV-1 transactivation inhibitors fall broadly into the following categories: (1) inhibitors targeting TAR RNA (2), inhibitors targeting Tat protein, and (3) Tat-P-TEFb interaction inhibitors. In this section, we review the current status of the development of therapeutic strategies that target 
TABLE 2: Tat-based therapeutics.

\begin{tabular}{|c|c|c|}
\hline Compound/class & Mechanism of action & Reference(s) \\
\hline $\mathrm{DRB}$ & Purine nucleoside analog; inhibits cyclin-dependent kinases & {$[23]$} \\
\hline Flavopiridol (flavonoids) & Inhibits cyclin-dependent kinases & {$[24]$} \\
\hline Seliciclib & Inhibits cyclin-dependent kinases & {$[25]$} \\
\hline 2'-O-Methyl/LNA oligoribonucleotides & Binds TAR & {$[26]$} \\
\hline Phosphodiester/phophothiote oligonucleotides & Binds TAR & [27] \\
\hline PNA-(TAR-16) & Polyamide nucleotide analog; binds TAR & {$[28]$} \\
\hline Acetylpromazine & Binds $5^{\prime}$ bulge of TAR & [29] \\
\hline $\mathrm{O}, \mathrm{O}^{\prime}$-Bismyristoyl thiamine disulfide & $\begin{array}{l}\text { Inhibits nuclear translocation of Tan and NF- } \kappa \mathrm{B} \text {, via interaction with } \\
\text { cysteine region }\end{array}$ & {$[30]$} \\
\hline Cyclic peptides & Mimics basic region and binds TAR & {$[31]$} \\
\hline Tat 9-K-biotin peptide & Binds TAR & {$[32]$} \\
\hline CGP64222 & Peptoid/peptide similar to Tat-basic domain; binds TAR & {$[33]$} \\
\hline CGP40336A (polyamine-acridine based) & Binds TAR & {$[34]$} \\
\hline Aminoglycoside-arginine conjugates & Binds TAR in the major groove of the bulge and upper portion of the stem & {$[35]$} \\
\hline Transdominant Tat mutants & Binds TAR & {$[36]$} \\
\hline Biscationic diphenylfuran derivatives & Binds TAR & {$[35]$} \\
\hline Neomycin (aminoglycoside) & Binds TAR, CXCR4, and other Tat targets & {$[37]$} \\
\hline D-penicillamine & Binds Tat stably through cysteine residues & {$[38]$} \\
\hline Stilbene (CGA137053) & Binds Tat directly & [39] \\
\hline Suramin and derivatives & $\begin{array}{l}\text { Competes with heparin/heparin sulfate for binding to the basic region of } \\
\text { Tat; inhibits extracellular functions of Tat }\end{array}$ & {$[40]$} \\
\hline Benzodiazepine derivatives & General inhibition of HIV-1 transcription and Tat transactivation & {$[41,42]$} \\
\hline Benzothiophene derivatives & - & {$[43]$} \\
\hline Temacrazine (bistriazolonoacridones) & - & {$[44]$} \\
\hline Fluoroquinolone derivatives & - & {$[45,46]$} \\
\hline
\end{tabular}

Tat and its functional interactions in the process of HIV-1 transcription (Table 2).

Compounds against the TAR RNA are the most numerous because they would block the primary functional interaction of Tat in the process of HIV-1 transcription. In this category, the compounds can be broadly divided into three classes: (1) peptide based, (2) oligonucleotide based, and (3) small-molecule based (for more detailed information refer to a previously published review [176]). It is well established that the arginine-rich motif of the Tat protein is required for it to bind to the TAR RNA trinucleotide bulge region $[15,90,177]$. Peptides corresponding to this region were found to compete for Tat binding and were shown to inhibit HIV-1 replication [32, 178]. Compounds directly binding to the three-base bulge of TAR RNA include 6aminoquinolone [179, 180], quinoxaline-2, 3-diones [181], pyridine oxide derivatives such as JPL-32 [182, 183], and acridine derivatives such as CGP64222 and CGP40336A [33, 34]. All of these compounds exhibit strong inhibition of the Tat-TAR interaction by binding to the three-base bulge of TAR RNA. The peptide CGP64222 was later shown also to interact with CXCR4 [184], the chemokine receptor that acts as a coreceptor for the X4 or dual tropic HIV-1 strains. Other drugs that specifically interact with the bulge in TAR RNA include biscationic diphenylfuran derivatives and a new class of polyamine-acridine-based compounds [34, 185]. Aminoglycoside antibiotics such as neomycin and streptomycin and neamine and its derivatives have been shown to specifically bind RNA molecules and to block the conformation of the Tat-TAR complex by targeting the structure of TAR RNA [181, 186, 187]. Besides the aforementioned Tat-TAR inhibition strategies, the developments in the field of RNA interference have yet to be applied in full force for achieving a more targeted inhibition [188, 189].

Compounds binding directly to the Tat protein could inhibit HIV-1 replication. To achieve this goal, targeting the basic domain of Tat would be relevant because this very domain is required for nuclear localization, transactivation through TAR binding, and also for extracellular release and cellular uptake [190, 191]. It has been shown that, in the extracellular compartment, the basic domain of Tat can be targeted by several polyanions [192] such as heparin and heparan sulfates [40], thrombospondin [193], polysulfonated distamycin A derivatives [194], and sulfated polysaccharides [195], thereby blocking its internalization and also its extracellular activities. Another compound targeting Tat is the negatively charged polyacrylic acid, which could inhibit the Tat-TAR interaction with high affinity to Tat peptide, thereby blocking HIV-1 replication [196]. Negatively charged small molecules, such as the stilbene derivative, CGA-137053, was shown to inhibit HIV-1 replication by directly binding to Tat and inhibiting the formation of the Tat-TAR complex at low nanomolar concentrations [39]. One important aspect, which must be considered, is 
that most of these interactions are largely due to electrostatic interactions with limited sequence specificity. Therefore, it would be highly relevant to evaluate their specificity in a relevant model system before they can be exploited in any therapeutic intervention strategy. Some transdominantnegative Tat mutants have also been shown to be potential antiviral therapeutics because they could inhibit the transactivation function of Tat, thereby inducing latency during viral infection [197-200]. Moreover, various biopolymeric drugs and anti-Tat antibodies have been demonstrated to be effective in inhibiting the extracellular activity and cellular uptake of Tat protein [176, 201]. Thus, targeting specific, conserved conformational epitopes on Tat might prove to be more beneficial. This approach can be aided tremendously by the emerging structural data on Tat. Some insights have already been provided by ab initio molecular dynamic studies on the Tat NMR structure and structural conformations of TAR [202, 203]. It would also be relevant to evaluate combination drug formulations to achieve an inhibition of the functional interactions of Tat at several levels [204]. This combination approach may also facilitate strategies that use relatively lower concentrations of these compounds that might improve overall toxicity levels. It might also be useful in targeting the small pool of latently infected cells that may hinder clearing the virus from the system.

The third approach is to use the understanding of the Tat$\mathrm{P}-\mathrm{TEFb}$ interaction to develop interventions to disrupt this interaction or to reduce the stability of this complex. P-TEFb (CDK9/cyclin T1) is an essential cofactor for Tat-mediated transactivation, and selective inhibition blocks HIV-1 replication without affecting cellular transcription, thus making it a potential target for anti-HIV-1 therapy. To this end, $\mathrm{P}-\mathrm{TEFb}$ inhibitors such as 5,6-dichlororibofuranosylbenzimidazole, a purine nucleoside analogue; flavopiridol, a small molecular cyclin-dependent kinase inhibitor [23, 24]; Seliciclib, an inhibitior of CDK2/cyclin E and/or P-TEFb [25] have been evaluated in various in vitro studies and have been shown to effectively reduce HIV-1 replication. However, long-term HIV-1 replication studies showed that these inhibitors were more cytotoxic and less efficacious against HIV-1 in the primary cell cultures [205]. The failure of these known kinase inhibitors in providing anti-HIV efficacy has prompted studies to revisit the Tat-P-TEFb complex for small molecule inhibitors. In this study, molecular dynamics simulations are being utilized to understand the nature of interactions of Tat with CDK9 and Cyclin-T1 in a dynamic mode. These interactions are further mapped on to a pharmacophore-based screening paradigm to design small molecule inhibitors that show potent HIV-1 efficacy and low toxicity (Kortagere and Wigdahl, unpublished results).

In alternative approaches, promising results were demonstrated using anti-CycT1 human single-chain antibodies that targeted the cyclin domain and the TAR recognition motif, using transiently transfected cell lines [132] and stably transfected cells [206]. Protein chimeras like fusion of a truncated human CycT1 and a mutant CDK9 protein that lacked autophosphorylation activity have demonstrated the inhibition of Tat-mediated transactivation and HIV-1 gene expression [207]. Intracellular proteins that inhibit P-TEFb-like HEXIM1 have been evaluated to suppress HIV-1 replication [208, 209]. Moreover, the inhibition of a transcriptional coactivator like PCAF has been evaluated using antibodies against the bromodomain of PCAF [210]. These studies establish a therapeutic rationale, but more specificity is desired because targeting proteins involved in cellular homeostasis and activation pathways may have detrimental effects on the cells. The same complexity applies to studies that propose targeting specific posttranslation modifications on Tat such as phosphorylation [211] and acetylation [107]. Moreover, most of these studies are done in irrelevant cell types that dilute their therapeutic promise. Another aspect that gets overlooked is that it is extremely difficult to evaluate this effect since any such intervention will have an impact on normal cellular pathways. This underscores the value of in-depth analysis of the functional interactions in the HIV-1 replication paradigm because it would yield more specific targets with minimal host toxicity. Another aspect that has not been investigated in detail is the genetic variations observed within the Tat-coding sequences and how they might impact the structure and function of this vital transactivator. Efforts in our laboratory and others have indicated variation in the transactivation potential of different Tat sequences from HIV-1-infected patients (unpublished observations). Moreover, it has been established that sequence variation within specific domains of Tat was associated with increased viral replication and TNF- $\alpha$ production $[141,166,212,213]$. These observations along with results that have shown that some Tat sequences exhibit minimal transactivation potential but have an ability to activate host gene expression [173] provide new directions where this aspect of Tat sequence variability can be included in strategies directed against Tat. The ideal outcome would be to achieve a competitive inhibition by using defective Tat mutants to inhibit Tat function, but a thorough understanding selected aspects of Tat function is a prerequisite to this line of investigation. These efforts again will be aided immensely by incorporating testing that includes Tat sequence and functional information across subtypes.

\section{Conclusions}

More than two decades of investigations have established the central role of Tat in the activation of HIV-1 LTR. Genetic- and structure/function-based studies have enabled us to understand the functional intricacies of Tat-dependent functions. All of these studies have motivated a number of researchers to use Tat as an important target in combination antiretroviral therapies, but to date none of these have materialized into clinically effective antiviral agents. One crippling factor has been the inability to assess the functions of Tat in relevant systems at a concentration that would be closer to that encountered in vivo. Concentrating efforts in a direction to elucidate the protein-protein interactome established by Tat will go a long way toward targeting specific breakpoints in HIV-1 pathogenesis. Isolation of mutant sequences of Tat from sites like the brain can also be used to identify tissue-specific functions of Tat that may have great bearing 
on long-term use of Tat inhibitors. Moreover, it would be an important effort to consolidate studies concerning the structural information and functional interactions of Tat across different HIV subtypes and use this information to increase the spectrum of subtypes susceptible to Tat-based therapeutic inhibitors. Eradicating latent reservoirs by the elimination of integrated HIV-1 provirus or irreversibly blocking LTR activation or Tat transactivation activity will provide the next major step forward in controlling the HIV-1 pandemic.

\section{Authors' Contribution}

Luna Li and Satinder Dahiya contributed equally in the preparation of this paper.

\section{Acknowledgments}

M. Nonnemacher, V. Pirrone, and B. Wigdahl are supported in part by funds from the Public Health Service, National Institutes of Health through grants from the National Institute of Neurological Disorders and Stroke, NS32092 and NS46263 (B. Wigdahl, Principal Investigator), and the National Institute of Drug Abuse, DA19807 (B. Wigdahl, Principal Investigator). Drs. M. Nonnemacher and S. Kortagere are supported by research developmental funds provided by the Department of Microbiology and Immunology and the Institute for Molecular Medicine and Infectious Disease, Drexel University College of Medicine. The authors would also like to acknowledge the editorial assistance of Pamela Fried in Academic Publishing Services of the Drexel University College of Medicine.

\section{References}

[1] J. A. Garcia, D. Harrich, E. Soultanakis, F. Wu, R. Mitsuyasu, and R. B. Gaynor, "Human immunodeficiency virus type 1 LTR TATA and TAR region sequences required for transcriptional regulation," EMBO Journal, vol. 8, no. 3, pp. 765-778, 1989.

[2] T. M. Rana and K. T. Jeang, "Biochemical and functional interactions between HIV-1 Tat protein and TAR RNA," Archives of Biochemistry and Biophysics, vol. 365, no. 2, pp. 175-185, 1999.

[3] B. N. Fields, D. M. Knipe, and P. M. Howley, Fields' Virology, Lippincott Williams \& Wilkins, Philadelphia, Pa, USA, 5th edition, 2007.

[4] K. T. Jeang, H. Xiao, and E. A. Rich, "Multifaceted activities of the HIV-1 transactivator of transcription, tat," Journal of Biological Chemistry, vol. 274, no. 41, pp. 28837-28840, 1999.

[5] F. Barre-Sinoussi, J. C. Chermann, and F. Rey, "Isolation of a T-lymphotropic retrovirus from a patient at risk for acquired immune deficiency syndrome (AIDS)," Science, vol. 220, no. 4599, pp. 868-871, 1983.

[6] C. A. Rosen, J. G. Sodroski, and W. C. Goh, "Posttranscriptional regulation accounts for the trans-activation of the human T-lymphotropic virus type III," Nature, vol. 319, no. 6054, pp. 555-559, 1986.

[7] M. Strazza, V. Pirrone, B. Wigdahl, and M. R. Nonnemacher, "Breaking down the barrier: the effects of HIV-1 on the blood-brain barrier," Brain Research, vol. 1399, pp. 96-115, 2011.

[8] M. R. López-Huertas, S. Callejas, D. Abia et al., "Modifications in host cell cytoskeleton structure and function mediated by intracellular HIV-1 Tat protein are greatly dependent on the second coding exon," Nucleic Acids Research, vol. 38, no. 10, pp. 3287-3307, 2010.

[9] M. Kuppuswamy, T. Subramanian, A. Srinivasan, and G. Chinnadurai, "Multiple functional domains of tat, the transactivator of HIV-1, defined by mutational analysis," Nucleic Acids Research, vol. 17, no. 9, pp. 3551-3561, 1989.

[10] P. Kalantari, V. Narayan, S. K. Natarajan et al., "Thioredoxin reductase-1 negatively regulates HIV-1 transactivating protein Tat-dependent transcription in human macrophages," Journal of Biological Chemistry, vol. 283, no. 48, pp. 3318333190, 2008.

[11] C. Dingwall, I. Ernberg, M. J. Gait et al., "Human immunodeficiency virus 1 Tat protein binds trans-activationresponsive region (TAR) RNA in vitro," Proceedings of the National Academy of Sciences of the United States of America, vol. 86, no. 18, pp. 6925-6929, 1989.

[12] S. Roy, U. Delling, C. H. Chen, C. A. Rosen, and N. Sonenberg, "A bulge structure in HIV-1 TAR RNA is required for Tat binding and Tat-mediated trans-activation," Genes and Development, vol. 4, no. 8, pp. 1365-1373, 1990.

[13] K. M. Weeks and D. M. Crothers, "RNA recognition by Tatderived peptides: interaction in the major groove?" Cell, vol. 66, no. 3, pp. 577-588, 1991.

[14] S. Ruben, A. Perkins, R. Purcell et al., "Structural and functional characterization of human immunodeficiency virus Tat protein," Journal of Virology, vol. 63, no. 1, pp. 1-8, 1989.

[15] J. Hauber, M. H. Malim, and B. R. Cullen, "Mutational analysis of the conserved basic domain of human immunodeficiency virus Tat protein," Journal of Virology, vol. 63, no. 3, pp. 1181-1187, 1989.

[16] S. R. Schwarze, K. A. Hruska, and S. F. Dowdy, "Protein transduction: unrestricted delivery into all cells?" Trends in Cell Biology, vol. 10, no. 7, pp. 290-295, 2000.

[17] S. R. Schwarze and S. F. Dowdy, "In vivo protein transduction: intracellular delivery of biologically active proteins, compounds and DNA," Trends in Pharmacological Sciences, vol. 21, no. 2, pp. 45-48, 2000.

[18] S. M. Smith, S. Pentlicky, Z. Klase et al., "An in vivo replication-important function in the second coding exon of Tat is constrained against mutation despite cytotoxic T lymphocyte selection," Journal of Biological Chemistry, vol. 278, no. 45, pp. 44816-44825, 2003.

[19] V. Fiorelli, G. Barillari, E. Toschi et al., "IFN- $\gamma$ induces endothelial cells to proliferate and to invade the extracellular matrix in response to the HIV-1 Tat protein: implications for AIDS-Kaposi's sarcoma pathogenesis," Journal of Immunology, vol. 162, no. 2, pp. 1165-1170, 1999.

[20] G. Barillari, C. Sgadari, V. Fiorelli et al., "The Tat protein of human immunodeficiency virus type-1 promotes vascular cell growth and locomotion by engaging the $\alpha 5 \beta 1$ and $\alpha v \beta 3$ integrins and by mobilizing sequestered basic fibroblast growth factor," Blood, vol. 94, no. 2, pp. 663-672, 1999.

[21] C. Neuveut, R. M. Scoggins, D. Camerini, R. B. Markham, and K. T. Jeang, "Requirement for the second coding exon of Tat in the optimal replication of macrophage-tropic HIV-1," Journal of Biomedical Science, vol. 10, no. 6, part 1, pp. 651660, 2003.

[22] U. Mahlknecht, I. Dichamp, A. Varin, C. van Lint, and G. Herbein, "NF- $\kappa$ B-dependent control of HIV-1 transcription 
by the second coding exon of Tat in T cells," Journal of Leukocyte Biology, vol. 83, no. 3, pp. 718-727, 2008.

[23] S. H. Chao, K. Fujinaga, J. E. Marion et al., "Flavopiridol inhibits P-TEFb and blocks HIV-1 replication," Journal of Biological Chemistry, vol. 275, no. 37, pp. 28345-28348, 2000.

[24] H. S. Y. Mancebo, G. Lee, J. Flygare et al., "P-TEFb kinase is required for HIV Tat transcriptional activation in vivo and in vitro," Genes and Development, vol. 11, no. 20, pp. 2633-2644, 1997.

[25] C. Benson, J. White, J. de Bono et al., "A phase I trial of the selective oral cyclin-dependent kinase inhibitor seliciclib (CYC202; R-Roscovitine), administered twice daily for 7 days every 21 days," British Journal of Cancer, vol. 96, no. 1, pp. 29-37, 2007.

[26] A. Arzumanov, A. P. Walsh, V. K. Rajwanshi, R. Kumar, J. Wengel, and M. J. Gait, "Inhibition of HIV-1 Tat-dependent trans activation by steric block chimeric 2'-O-methyl/LNA oligoribonucleotides," Biochemistry, vol. 40, no. 48, pp. 14645-14654, 2001.

[27] T. Vickers, B. F. Baker, P. D. Cook et al., "Inhibition of HIVLTR gene expression by oligonucleotides targeted to the TAR element," Nucleic Acids Research, vol. 19, no. 12, pp. 33593368, 1991.

[28] N. Kaushik, A. Basu, and V. N. Pandey, "Inhibition of HIV1 replication by anti-trans-activation responsive polyamide nucleotide analog," Antiviral Research, vol. 56, no. 1, pp. 1327, 2002.

[29] K. E. Lind, Z. Du, K. Fujinaga, B. M. Peterlin, and T. L. James, "Structure-based computational database screening, in vitro assay, and NMR assessment of compounds that target TAR RNA," Chemistry and Biology, vol. 9, no. 2, pp. 185-193, 2002.

[30] S. Shoji, K. Furuishi, A. Ogata et al., "An allosteric drug, o,o'bismyristoyl thiamine disulfide, suppresses HIV-1 replication through prevention of nuclear translocation of both HIV1 Tat and NF- $\kappa$ B," Biochemical and Biophysical Research Communications, vol. 249, no. 3, pp. 745-753, 1998.

[31] A. Friedler, D. Friedler, N. W. Luedtke, Y. Tor, A. Loyter, and C. Gilon, "Development of a functional backbone cyclic mimetic of the HIV-1 Tat arginine-rich motif," Journal of Biological Chemistry, vol. 275, no. 31, pp. 23783-23789, 2000.

[32] I. Choudhury, J. Wang, A. B. Rabson et al., "Inhibition of HIV-1 replication by a Tat RNA-binding domain peptide analog," Journal of Acquired Immune Deficiency Syndromes and Human Retrovirology, vol. 17, no. 2, pp. 104-111, 1998.

[33] F. Hamy, E. R. Felder, G. Heizmann et al., "An inhibitor of the Tat/TAR RNA interaction that effectively suppresses HIV1 replication," Proceedings of the National Academy of Sciences of the United States of America, vol. 94, no. 8, pp. 3548-3553, 1997.

[34] F. Hamy, V. Brondani, A. Flörsheimer, W. Stark, M. J. J. Blommers, and T. Klimkait, "A new class of HIV-1 Tat antagonist acting through Tat-TAR inhibition," Biochemistry, vol. 37, no. 15, pp. 5086-5095, 1998.

[35] N. Gelus, C. Bailly, F. Hamy, T. Klimkait, W. D. Wilson, and D. W. Boykin, "Inhibition of HIV-1 Tat-TAR interaction by diphenylfuran derivatives: effects of the terminal basic side chains," Bioorganic and Medicinal Chemistry, vol. 7, no. 6, pp. 1089-1096, 1999.

[36] L. Pearson, J. Garcia, F. Wu, N. Modesti, J. Nelson, and R. Gaynor, "A transdominant Tat mutant that inhibits Tatinduced gene expression from the human immunodeficiency virus long terminal repeat," Proceedings of the National Academy of Sciences of the United States of America, vol. 87, no. 13, pp. 5079-5083, 1990.
[37] A. Litovchick, A. Lapidot, M. Eisenstein, A. Kalinkovich, and G. Borkow, "Neomycin B-arginine conjugate, a novel HIV-1 Tat antagonist: synthesis and anti-HIV activities," Biochemistry, vol. 40, no. 51, pp. 15612-15623, 2001.

[38] A. Chandra, I. Demirhan, S. K. Arya, and P. Chandra, "Dpenicillamine inhibits transactivation of human immunodeficiency virus type-1 (HIV-1) LTR by transactivator protein," FEBS Letters, vol. 236, no. 2, pp. 282-286, 1988.

[39] F. Hamy, N. Gelus, M. Zeller, J. L. Lazdins, C. Bailly, and T. Klimkait, "Blocking HIV replication by targeting Tat protein," Chemistry and Biology, vol. 7, no. 9, pp. 669-676, 2000.

[40] M. Rusnati, G. Tulipano, D. Spillmann et al., "Multiple interactions of HIV-I Tat protein with size-defined heparin oligosaccharides," Journal of Biological Chemistry, vol. 274, no. 40, pp. 28198-28205, 1999.

[41] M. C. Hsu, U. Dhingra, J. V. Earley et al., "Inhibition of type 1 human immunodeficiency virus replication by a Tat antagonist to which the virus remains sensitive after prolonged exposure in vitro," Proceedings of the National Academy of Sciences of the United States of America, vol. 90, no. 14, pp. 6395-6399, 1993.

[42] M. C. Hsu, A. D. Schutt, M. Holly et al., "Inhibition of HIV replication in acute and chronic infections in vitro by a Tat antagonist," Science, vol. 254, no. 5039, pp. 1799-1802, 1991.

[43] S. T. Butera, B. D. Roberts, J. W. Critchfield et al., "Compounds that target novel cellular components involved in HIV-1 transcription," Molecular Medicine, vol. 1, no. 7, pp. 758-767, 1995.

[44] J. A. Turpin, R. W. Buckheit, D. Derse et al., "Inhibition of acute-, latent-, and chronic-phase human immunodeficiency virus type 1 (HIV-1) replication by a bistriazoloacridone analog that selectively inhibits HIV-1 transcription," Antimicrobial Agents and Chemotherapy, vol. 42, no. 3, pp. 487-494, 1998.

[45] M. Baba, M. Okamoto, M. Makino et al., "Potent and selective inhibition of human immunodeficiency virus type 1 transcription by piperazinyloxoquinoline derivatives," Antimicrobial Agents and Chemotherapy, vol. 41, no. 6, pp. 12501255, 1997.

[46] M. Baba, M. Okamoto, M. Kawamura et al., "Inhibition of human immunodeficiency virus type 1 replication and cytokine production by fluoroquinoline derivatives," Molecular Pharmacology, vol. 53, no. 6, pp. 1097-1103, 1998.

[47] L. A. Pereira, K. Bentley, A. Peeters, M. J. Churchill, and N. J. Deacon, "A compilation of cellular transcription factor interactions with the HIV-1 LTR promoter," Nucleic Acids Research, vol. 28, no. 3, pp. 663-668, 2000.

[48] C. M. Chiang, H. Ge, Z. Wang, A. Hoffman, and G. Roeder, "Unique TATA-binding protein-containing complexes and cofactors involved in transcription by RNA polymerases II and III," EMBO Journal, vol. 12, no. 7, pp. 2749-2762, 1993.

[49] J. R. Huh, J. M. Park, M. Kim, B. A. Carlson, D. L. Hatfield, and B. J. Lee, "Recruitment of TBP or TFIIB to a promoter proximal position leads to stimulation of RNA polymerase II transcription without activator proteins both in vivo and in vitro," Biochemical and Biophysical Research Communications, vol. 256, no. 1, pp. 45-51, 1999.

[50] Y. H. Ping and T. M. Rana, "DSIF and NELF interact with RNA polymerase II elongation complex and HIV-1 Tat stimulates P-TEFb-mediated phosphorylation of RNA polymerase II and DSIF during transcription elongation," Journal of Biological Chemistry, vol. 276, no. 16, pp. 12951-12958, 2001. 
[51] C. B. Phelps, L. L. Sengchanthalangsy, S. Malek, and G. Ghosh, "Mechanism of $\kappa \mathrm{B}$ DNA binding by Rel/NF- $\kappa \mathrm{B}$ dimers," Journal of Biological Chemistry, vol. 275, no. 32, pp. 24392-24399, 2000.

[52] Y. Liu, M. R. Nonnemacher, and B. Wigdahl, "CCAAT/ enhancer-binding proteins and the pathogenesis of retrovirus infection," Future Microbiology, vol. 4, no. 3, pp. 299-321, 2009.

[53] H. L. Ross, S. Gartner, J. C. McArthur et al., "HIV-1 LTR $\mathrm{C} / \mathrm{EBP}$ binding site sequence configurations preferenstially encountered in brain lead to enhanced C/EBP factor binding and increased LTR-specific activity," Journal of NeuroVirology, vol. 7, no. 3, pp. 235-249, 2001.

[54] S. Ranjbar, A. V. Tsytsykova, S. K. Lee et al., "NFAT5 regulates HIV-1 in primary monocytes via a highly conserved long terminal repeat site," PLoS Pathogens, vol. 2, no. 12, article e130, 2006.

[55] A. J. Henderson and K. L. Calame, "CCAAT/enhancer binding protein (C/EBP) sites are required for HIV-1 replication in primary macrophages but not $\mathrm{CD} 4^{+} \mathrm{T}$ cells," Proceedings of the National Academy of Sciences of the United States of America, vol. 94, no. 16, pp. 8714-8719, 1997.

[56] E. M. Kilareski, S. Shah, M. R. Nonnemacher, and B. Wigdahl, "Regulation of HIV-1 transcription in cells of the monocyte-macrophage lineage," Retrovirology, vol. 6, article 118, 2009.

[57] F. C. Krebs, M. M. Goodenow, and B. Wigdahl, "Neuroglial ATF/CREB factors interact with the human immunodeficiency virus type 1 long terminal repeat," Journal of NeuroVirology, vol. 3, supplement 1, pp. S28-S32, 1997.

[58] S. Shah, M. R. Nonnemacher, V. Pirrone, and B. Wigdahl, "Innate and adaptive factors regulating human immunodeficiency virus type 1 genomic activation," Journal of Neuroimmune Pharmacology, vol. 5, no. 3, pp. 278-293, 2010.

[59] B. Alberts, A. Johnson, J. Lewis, M. Raff, K. Roberts, and P. Walter, Molecular Biology of the Cell, 2002.

[60] E. Verdin, P. Paras Jr., and C. van Lint, "Chromatin disruption in the promoter of human immunodeficiency virus type 1 during transcriptional activation," EMBO Journal, vol. 12, no. 8, pp. 3249-3259, 1993.

[61] E. Verdin, "DNase I-hypersensitive sites are associated with both long terminal repeats and with the intragenic enhancer of integrated human immunodeficiency virus type 1," Journal of Virology, vol. 65, no. 12, pp. 6790-6799, 1991.

[62] K. A. Jones and B. M. Peterlin, "Control of RNA initiation and elongation at the HIV-1 promoter," Annual Review of Biochemistry, vol. 63, pp. 717-743, 1994.

[63] C. van Lint, C. A. Amella, S. Emiliani, M. John, T. Jie, and E. Verdin, "Transcription factor binding sites downstream of the human immunodeficiency virus type 1 transcription start site are important for virus infectivity," Journal of Virology, vol. 71, no. 8, pp. 6113-6127, 1997.

[64] A. Pumfery, L. Deng, A. Maddukuri et al., "Chromatin remodeling and modification during HIV-1 Tat-activated transcription," Current HIV Research, vol. 1, no. 3, pp. 343$362,2003$.

[65] S. L. Berger, "Histone modifications in transcriptional regulation," Current Opinion in Genetics and Development, vol. 12, no. 2, pp. 142-148, 2002.

[66] M. P. Cosma, "Ordered recruitment: gene-specific mechanism of transcription activation," Molecular Cell, vol. 10, no. 2, pp. 227-236, 2002.

[67] S. A. Williams, L. F. Chen, H. Kwon, C. M. Ruiz-Jarabo, E. Verdin, and W. C. Greene, "NF- $\kappa$ B p50 promotes HIV latency through HDAC recruitment and repression of transcriptional initiation," EMBO Journal, vol. 25, no. 1, pp. 139-149, 2006.

[68] J. J. Coull, F. Romerio, J. M. Sun et al., "The human factors YY1 and LSF repress the human immunodeficiency virus type 1 long terminal repeat via recruitment of histone deacetylase 1," Journal of Virology, vol. 74, no. 15, pp. 67906799, 2000

[69] W. Fischle, S. Emiliani, M. J. Hendzel et al., "A new family of human histone deacetylases related to Saccharomyces cerevisiae HDA1p," Journal of Biological Chemistry, vol. 274, no. 17, pp. 11713-11720, 1999.

[70] A. J. Bannister, P. Zegerman, J. F. Partridge et al., "Selective recognition of methylated lysine 9 on histone $\mathrm{H} 3$ by the HP1 chromo domain," Nature, vol. 410, no. 6824, pp. 120-124, 2001.

[71] T. Cheutin, A. J. McNairn, T. Jenuwein, D. M. Gilbert, P. B. Singh, and T. Misteli, "Maintenance of stable heterochromatin domains by dynamic HP1 binding," Science, vol. 299, no. 5607, pp. 721-725, 2003.

[72] S. I. S. Grewal and D. Moazed, "Heterochromatin and epigenetic control of gene expression," Science, vol. 301, no. 5634, pp. 798-802, 2003.

[73] T. Ishida, A. Hamano, T. Koiwa, and T. Watanabe, “ 5 ' long terminal repeat (LTR)-selective methylation of latently infected HIV-1 provirus that is demethylated by reactivation signals," Retrovirology, vol. 3, article 69, 2006.

[74] K. F. T. Copeland, "Modulation of HIV-1 transcription by cytokines and chemokines," Mini-Reviews in Medicinal Chemistry, vol. 5, no. 12, pp. 1093-1101, 2005.

[75] F. C. Krebs, S. R. Miller, B. J. Catalone et al., "Comparative in vitro sensitivities of human immune cell lines, vaginal and cervical epithelial cell lines, and primary cells to candidate microbicides nonoxynol 9, C31G, and sodium dodecyl sulfate," Antimicrobial Agents and Chemotherapy, vol. 46, no. 7, pp. 2292-2298, 2002.

[76] K. Lassen, Y. Han, Y. Zhou, J. Siliciano, and R. F. Siliciano, "The multifactorial nature of HIV-1 latency," Trends in Molecular Medicine, vol. 10, no. 11, pp. 525-531, 2004.

[77] J. O. Liu, “The yins of T cell activation," Science's STKE, vol. 2005, no. 265, p. re1, 2005.

[78] J. Brady and F. Kashanchi, "Tat gets the "green" light on transcription initiation," Retrovirology, vol. 2, article 69, 2005.

[79] A. I. Dayton, J. G. Sodroski, and C. A. Rosen, "The transactivator gene of the human T cell lymphotropic virus type III is required for replication," Cell, vol. 44, no. 6, pp. 941947, 1986.

[80] A. G. Fisher, M. B. Feinberg, and S. F. Josephs, "The transactivator gene of HTLV-III is essential for virus replication," Nature, vol. 320, no. 6060, pp. 367-371, 1986.

[81] M. F. Laspia, A. P. Rice, and M. B. Mathews, "Synergy between HIV-1 Tat and adenovirus E1A is principally due to stabilization of transcriptional elongation," Genes and Development, vol. 4, no. 12, pp. 2397-2408, 1990.

[82] S. Ghosh, M. J. Selby, and B. M. Peterlin, "Synergism between Tat and VP16 in trans-activation of HIV-1 LTR," Journal of Molecular Biology, vol. 234, no. 3, pp. 610-619, 1993.

[83] T. P. Cujec, H. Okamoto, K. Fujinaga et al., "The HIV transactivator Tat binds to the CDK-activating kinase and activates the phosphorylation of the carboxy-terminal domain of RNA polymerase II," Genes and Development, vol. 11, no. 20, pp. 2645-2657, 1997. 
[84] L. F. García-Martínez, G. Mavankal, J. M. Neveu, W. S. Lane, D. Ivanov, and R. B. Gaynor, "Purification of a Tatassociated kinase reveals a TFIIH complex that modulates HIV-1 transcription," EMBO Journal, vol. 16, no. 10, pp. 2836-2850, 1997.

[85] C. A. Parada and R. G. Roeder, "Enhanced processivity of RNA polymerase II triggered by Tat-induced phosphorylation of its carboxy-terminal domain," Nature, vol. 384, no. 6607, pp. 375-378, 1996.

[86] B. Berkhout, R. H. Silverman, and K. T. Jeang, "Tat transactivates the human immunodeficiency virus through a nascent RNA target," Cell, vol. 59, no. 2, pp. 273-282, 1989.

[87] M. A. Muesing, D. H. Smith, and D. J. Capon, "Regulation of mRNA accumulation by a human immunodeficiency virus trans-activator protein," Cell, vol. 48, no. 4, pp. 691-701, 1987.

[88] T. Raha, S. W. Cheng, and M. R. Green, "HIV-1 Tat stimulates transcription complex assembly through recruitment of TBP in the absence of TAFs," PLoS Biology, vol. 3, no. 2, article e44, 2005.

[89] M. J. Selby, E. S. Bain, P. A. Luciw, and B. M. Peterlin, "Structure, sequence, and position of the stem-loop in tar determine transcriptional elongation by Tat through the HIV-1 long terminal repeat," Genes \& Development, vol. 3, no. 4 , pp. 547-558, 1989.

[90] M. J. Churcher, C. Lamont, F. Hamy et al., "High affinity binding of TAR RNA by the human immunodeficiency virus type-1 Tat protein requires base-pairs in the RNA stem and amino acid residues flanking the basic region," Journal of Molecular Biology, vol. 230, no. 1, pp. 90-110, 1993.

[91] Y. Zhu, T. Pe'ery, J. Peng et al., "Transcription elongation factor P-TEFb is required for HIV-1 Tat transactivation in vitro," Genes and Development, vol. 11, no. 20, pp. 2622-2632, 1997.

[92] P. Wei, M. E. Garber, S. M. Fang, W. H. Fischer, and K. A. Jones, "A novel CDK9-associated C-type cyclin interacts directly with HIV-1 Tat and mediates its high-affinity, loopspecific binding to TAR RNA," Cell, vol. 92, no. 4, pp. 451$462,1998$.

[93] Q. Zhou, D. Chen, E. Pierstorff, and K. Luo, "Transcription elongation factor P-TEFb mediates Tat activation of HIV-1 transcription at multiple stages," EMBO Journal, vol. 17, no. 13, pp. 3681-3691, 1998.

[94] R. Ghose, L. Y. Liou, C. H. Herrmann, and A. P. Rice, "Induction of TAK (cyclin T1/P-TEFb) in purified resting $\mathrm{CD}^{+} \mathrm{T}$ lymphocytes by combination of cytokines," Journal of Virology, vol. 75, no. 23, pp. 11336-11343, 2001.

[95] S. Emiliani, W. Fischle, M. Ott, C. van Lint, C. A. Amella, and E. Verdin, "Mutations in the Tat gene are responsible for human immunodeficiency virus type 1 postintegration latency in the U1 cell line," Journal of Virology, vol. 72, no. 2, pp. 1666-1670, 1998.

[96] S. Emiliani, C. van Lint, W. Fischle et al., "A point mutation in the HIV-1 Tat responsive element is associated with postintegration latency," Proceedings of the National Academy of Sciences of the United States of America, vol. 93, no. 13, pp. 6377-6381, 1996.

[97] K. Yankulov and D. Bentley, "Transcriptional control: Tat cofactors and transcriptional elongation," Current Biology, vol. 8, no. 13, pp. R447-R449, 1998.

[98] C. Das, S. P. Edgcomb, R. Peteranderl, L. Chen, and A. D. Frankel, "Evidence for conformational flexibility in the TatTAR recognition motif of cyclin T1," Virology, vol. 318, no. 1, pp. 306-317, 2004.
[99] R. E. Jeeninga, M. Hoogenkamp, M. Armand-Ugon, M. de Baar, K. Verhoef, and B. Berkhout, "Functional differences between the long terminal repeat transcriptional promoters of human immunodeficiency virus type 1 subtypes A through G," Journal of Virology, vol. 74, no. 8, pp. 3740-3751, 2000.

[100] T. Kurosu, T. Mukai, W. Auwanit, P. I. N. Ayuthaya, S. SaengAroon, and K. Ikuta, "Variable sequences in the long terminal repeat and its downstream region of some of HIV type 1 CRF01_AE recently distributing among Thai carriers," AIDS Research and Human Retroviruses, vol. 17, no. 9, pp. 863-866, 2001.

[101] J. K. Carr, M. O. Salminen, C. Koch et al., "Full-length sequence and mosaic structure of a human immunodeficiency virus type 1 isolate from Thailand," Journal of Virology, vol. 70, no. 9, pp. 5935-5943, 1996.

[102] F. Gao, D. L. Robertson, S. G. Morrison et al., "The heterosexual human immunodeficiency virus type 1 epidemic in Thailand is caused by an intersubtype (A/E) recombinant of African origin," Journal of Virology, vol. 70, no. 10, pp. 70137029, 1996.

[103] M. A. Montano, V. A. Novitsky, J. T. Blackard, N. L. Cho, D. A. Katzenstein, and M. Essex, "Divergent transcriptional regulation among expanding human immunodeficiency virus type 1 subtypes," Journal of Virology, vol. 71, no. 11, pp. 86578665, 1997.

[104] E. R. de Arellano, V. Soriano, and A. Holguin, "Genetic analysis of regulatory, promoter, and TAR regions of LTR sequences belonging to HIV type 1 non-B subtypes," AIDS Research and Human Retroviruses, vol. 21, no. 11, pp. 949954, 2005.

[105] M. A. Montano, C. P. Nixon, and M. Essex, "Dysregulation through the NF- $\kappa \mathrm{B}$ enhancer and TATA box of the human immunodeficiency virus type 1 subtype E promoter," Journal of Virology, vol. 72, no. 10, pp. 8446-8452, 1998.

[106] T. J. Scriba, T. de Villiers, F. K. Treurnicht et al., "Characterization of the South African HIV type 1 subtype C complete 5' long terminal repeat, nef, and regulatory genes," AIDS Research and Human Retroviruses, vol. 18, no. 2, pp. 149-159, 2002.

[107] I. D'Orso and A. D. Frankel, “Tat acetylation modulates assembly of a viral-host RNA-protein transcription complex," Proceedings of the National Academy of Sciences of the United States of America, vol. 106, no. 9, pp. 3101-3106, 2009.

[108] K. Asamitsu, Y. Hibi, K. Imai et al., "Functional characterization of human cyclin T1 N-terminal region for human immunodeficiency virus-1 Tat transcriptional activation," Journal of Molecular Biology, vol. 410, no. 5, pp. 887-895, 2011.

[109] M. E. Dahmus, "Phosphorylation of the C-terminal domain of RNA polymerase II," Biochimica et Biophysica Acta, vol. 1261, no. 2, pp. 171-182, 1995.

[110] J. Q. Svejstrup, Y. Li, J. Fellows, A. Gnatt, S. Bjorklund, and R. D. Kornberg, "Evidence for a mediator cycle at the initiation of transcription," Proceedings of the National Academy of Sciences of the United States of America, vol. 94, no. 12, pp. 6075-6078, 1997.

[111] I. D’Orso, J. R. Grunwell, R. L. Nakamura, C. Das, and A. D. Frankel, "Targeting Tat inhibitors in the assembly of human immunodeficiency virus type 1 transcription complexes," Journal of Virology, vol. 82, no. 19, pp. 9492-9504, 2008.

[112] G. Marzio, M. Tyagi, M. I. Gutierrez, and M. Giacca, "HIV1 Tat transactivator recruits p300 and CREB-binding protein histone acetyltransferases to the viral promoter," Proceedings 
of the National Academy of Sciences of the United States of America, vol. 95, no. 23, pp. 13519-13524, 1998.

[113] A. E. L. Kharroubi and M. A. Martin, "cis-acting sequences located downstream of the human immunodeficiency virus type 1 promoter affect its chromatin structure and transcriptional activity," Molecular and Cellular Biology, vol. 16, no. 6, pp. 2958-2966, 1996.

[114] L. Deng, C. de la Fuente, P. Fu et al., "Acetylation of HIV-1 Tat by CBP/P300 increases transcription of integrated HIV1 genome and enhances binding to core histones," Virology, vol. 277, no. 2, pp. 278-295, 2000.

[115] M. Benkirane, R. F. Chun, H. Xiao et al., "Activation of integrated provirus requires histone acetyltransferase: p300 and P/CAF are coactivators for HIV-1 tat," Journal of Biological Chemistry, vol. 273, no. 38, pp. 24898-24905, 1998.

[116] V. Brès, R. Kiernan, S. Emiliani, and M. Benkirane, "Tat acetyl-acceptor lysines are important for human immunodeficiency virus type-1 replication," Journal of Biological Chemistry, vol. 277, no. 25, pp. 22215-22221, 2002.

[117] V. Brès, H. Tagami, J. M. Péloponèse et al., "Differential acetylation of Tat coordinates its interaction with the coactivators cyclin T1 and PCAF," EMBO Journal, vol. 21, no. 24, pp. 6811-6819, 2002.

[118] C. van Lint, S. Emiliani, M. Ott, and E. Verdin, "Transcriptional activation and chromatin remodeling of the HIV-1 promoter in response to histone acetylation," EMBO Journal, vol. 15, no. 5, pp. 1112-1120, 1996.

[119] B. Furia, L. Deng, K. Wu et al., "Enhancement of nuclear factor- $\kappa$ B acetylation by coactivator p300 and HIV-1 Tat proteins," Journal of Biological Chemistry, vol. 277, no. 7, pp. 4973-4980, 2002.

[120] C. J. Wilson, D. M. Chao, A. N. Imbalzano, G. R. Schnitzler, R. E. Kingston, and R. A. Young, "RNA polymerase II holoenzyme contains SWI/SNF regulators involved in chromatin remodeling," Cell, vol. 84, no. 2, pp. 235-244, 1996.

[121] C. L. Peterson and J. W. Tamkun, "The SWI-SNF complex: a chromatin remodeling machine," Trends in Biochemical Sciences, vol. 20, no. 4, pp. 143-146, 1995.

[122] C. Tréand, I. Du Chéné, V. Brès et al., "Requirement for SWI/SNF chromatin-remodeling complex in Tat-mediated activation of the HIV-1 promoter," EMBO Journal, vol. 25, no. 8, pp. 1690-1699, 2006.

[123] T. Mahmoudi, M. Parra, R. G. J. Vries et al., "The SWI/SNF chromatin-remodeling complex is a cofactor for Tat transactivation of the HIV promoter," Journal of Biological Chemistry, vol. 281, no. 29, pp. 19960-19968, 2006.

[124] A. Henderson, A. Holloway, R. Reeves, and D. J. Tremethick, "Recruitment of SWI/SNF to the human immunodeficiency virus type 1 promoter," Molecular and Cellular Biology, vol. 24, no. 1, pp. 389-397, 2004.

[125] K. Zhao, W. Wang, O. J. Rando et al., "Rapid and phosphoinositol-dependent binding of the SWI/SNF-like BAF complex to chromatin after $\mathrm{T}$ lymphocyte receptor signaling," Cell, vol. 95, no. 5, pp. 625-636, 1998.

[126] X. Shen, H. Xiao, R. Ranallo, W. H. Wu, and C. Wu, "Modulation of ATP-dependent chromatin-remodeling complexes by inositol polyphosphates," Science, vol. 299, no. 5603, pp. 112-114, 2003.

[127] D. J. Steger, E. S. Haswell, A. L. Miller, S. R. Wente, and E. K. O'Shea, "Regulation of chromatin remodeling by inositol polyphosphates," Science, vol. 299, no. 5603, pp. 114-116, 2003.
[128] K. T. Jeang, R. Chun, N. H. Lin, A. Gatignol, C. G. Glabe, and H. Fan, "In vitro and in vivo binding of human immunodeficiency virus type 1 Tat protein and Sp1 transcription factor," Journal of Virology, vol. 67, no. 10, pp. 6224-6233, 1993.

[129] R. F. Chun, O. J. Semmes, C. Neuveut, and K. T. Jeang, "Modulation of Sp1 phosphorylation by human immunodeficiency virus type 1 tat," Journal of Virology, vol. 72, no. 4, pp. 2615-2629, 1998.

[130] D. Chen and Q. Zhou, "Tat activates human immunodeficiency virus type 1 transcriptional elongation independent of TFIIH kinase," Molecular and Cellular Biology, vol. 19, no. 4, pp. 2863-2871, 1999.

[131] R. F. Siliciano and W. C. Greene, "HIV Latency," Cold Spring Harbor Perspectives in Medicine, vol. 1, no. 1, atricle a007096, 2011.

[132] K. Fujinaga, R. Taube, J. Wimmer, T. P. Cujec, and B. M. Peterlin, "Interactions between human cyclin T, tat, and the transactivation response element (TAR) are disrupted by a cysteine to tyrosine substitution found in mouse cyclin T," Proceedings of the National Academy of Sciences of the United States of America, vol. 96, no. 4, pp. 1285-1290, 1999.

[133] C. Ambrosino, M. R. Ruocco, X. Chen et al., "HIV-1 Tat induces the expression of the interleukin-6 (IL6) gene by binding to the IL6 leader RNA and by interacting with CAAT enhancer-binding protein $\beta$ (NF-IL6) transcription factors," Journal of Biological Chemistry, vol. 272, no. 23, pp. 1488314892, 1997.

[134] X. Liu, M. Jana, S. Dasgupta et al., "Human immunodeficiency virus type 1 (HIV-1) Tat induces nitric-oxide synthase in human astroglia," Journal of Biological Chemistry, vol. 277, no. 42, pp. 39312-39319, 2002.

[135] R. Mukerjee, B. E. Sawaya, K. Khalili, and S. Amini, "Association of $\mathrm{p} 65$ and C/EBP $\beta$ with HIV-1 LTR modulates transcription of the viral promoter," Journal of Cellular Biochemistry, vol. 100, no. 5, pp. 1210-1216, 2007.

[136] F. Macián and A. Rao, "Reciprocal modulatory interaction between human immunodeficiency virus type 1 Tat and transcription factor NFAT1," Molecular and Cellular Biology, vol. 19, no. 5, pp. 3645-3653, 1999.

[137] N. Kim, S. Kukkonen, S. Gupta, and A. Aldovini, "Association of Tat with promoters of PTEN and PP2A subunits is key to transcriptional activation of apoptotic pathways in HIVinfected CD4 ${ }^{+}$T cells," PLoS Pathogens, vol. 6, no. 9, article e01103, 2010.

[138] B. N. Fields et al., Fields' Virology, Lippincott Williams \& Wilkins, Philadelphia, Pa, USA, 4th edition, 2001.

[139] T. Zhu, H. Mo, N. Wang et al., "Genotypic and phenotypic characterization of HIV-1 in patients with primary infection," Science, vol. 261, no. 5125, pp. 1179-1181, 1993.

[140] S. Opi, J. M. Péloponèse, D. Esquieu et al., "Tat HIV-1 primary and tertiary structures critical to immune response against non-homologous variants," Journal of Biological Chemistry, vol. 277, no. 39, pp. 35915-35919, 2002.

[141] G. van Marle and C. Power, "Human immunodeficiency virus type 1 genetic diversity in the nervous system: evolutionary epiphenomenon or disease determinant?" Journal of NeuroVirology, vol. 11, no. 2, pp. 107-128, 2005.

[142] N. B. Siddappa, M. Venkatramanan, P. Venkatesh et al., "Transactivation and signaling functions of Tat are not correlated: biological and immunological characterization of HIV-1 subtype-C Tat protein," Retrovirology, vol. 3, article 53, 2006. 
[143] G. Turk, M. Carobene, A. Monczor, A. E. Rubio, M. GómezCarrillo, and H. Salomón, "Higher transactivation activity associated with LTR and Tat elements from HIV-I BF intersubtype recombinant variants," Retrovirology, vol. 3, article 14, 2006.

[144] T. Kurosu, T. Mukai, S. Komoto et al., "Human immunodeficiency virus type 1 subtype $\mathrm{C}$ exhibits higher transactivation activity of Tat than subtypes B and E," Microbiology and Immunology, vol. 46, no. 11, pp. 787-799, 2002.

[145] G. R. Campbell, J. D. Watkins, K. K. Singh, E. P. Loret, and S. A. Spector, "Human immunodeficiency virus type 1 subtype C Tat fails to induce intracellular calcium flux and induces reduced tumor necrosis factor production from monocytes," Journal of Virology, vol. 81, no. 11, pp. 5919-5928, 2007.

[146] U. Ranga, R. Shankarappa, N. B. Siddappa et al., "Tat protein of human immunodeficiency virus type 1 subtype $C$ strains is a defective chemokine," Journal of Virology, vol. 78, no. 5, pp. 2586-2590, 2004.

[147] U. Neogi, S. Gupta, P. N. Sahoo et al., "Genetic characterization of 5 HIV-1 Tat exon 1 from a southern Indian clinical cohort: identification of unique epidemiological signature residues," AIDS Research and Human Retroviruses. In press.

[148] L. Li, B. Aiamkitsumrit, V. Pirrone et al., "Development of co-selected single nucleotide polymorphisms in the viral promoter precedes the onset of human immunodeficiency virus type 1-associated neurocognitive impairment," Journal of NeuroVirology, vol. 17, no. 1, pp. 92-109, 2011.

[149] S. Spira, M. A. Wainberg, H. Loemba, D. Turner, and B. G. Brenner, "Impact of clade diversity on HIV-1 virulence, antiretroviral drug sensitivity and drug resistance," Journal of Antimicrobial Chemotherapy, vol. 51, no. 2, pp. 229-240, 2003.

[150] F. Gao, D. L. Robertson, C. D. Carruthers et al., "A comprehensive panel of near-full-length clones and reference sequences for non-subtype B isolates of human immunodeficiency virus type 1," Journal of Virology, vol. 72, no. 7, pp. 5680-5698, 1998.

[151] S. S. Dey, Y. Xue, M. P. Joachimiak et al., "Mutual information analysis reveals coevolving residues in Tat that compensate for two distinct functions in HIV-1 gene expression," The Journal of Biological Chemistry, vol. 287, no. 11, pp. 79457955, 2012.

[152] M. C. D. G. Huigen, W. Kamp, and H. S. L. M. Nottet, "Multiple effects of HIV-1 trans-activator protein on the pathogenesis of HIV-1 infection," European Journal of Clinical Investigation, vol. 34, no. 1, pp. 57-66, 2004.

[153] A. Banerjee, M. Strazza, and B. Wigdahl, "Role of mu-opioids as cofactors in human immunodeficiency virus type 1 disease progression and neuropathogenesis," Neurovirology, vol. 17, no. 4, pp. 291-302, 2011.

[154] I. L. Tan and J. C. McArthur, "HIV-associated neurological disorders: a guide to pharmacotherapy," CNS Drugs, vol. 26, no. 2, pp. 123-134, 2012.

[155] N. Z. Mothobi and B. J. Brew, "Neurocognitive dysfunction in the highly active antiretroviral therapy era," Current Opinion in Infectious Diseases, vol. 25, no. 1, pp. 4-9, 2012.

[156] C. Power, M. J. Gill, and R. T. Johnson, "Progress in clinical neurosciences: the neuropathogenesis of HIV infection: Host-virus interaction and the impact of therapy," Canadian Journal of Neurological Sciences, vol. 29, no. 1, pp. 19-32, 2002.

[157] S. L. Letendre, R. J. Ellis, B. M. Ances, and J. A. McCutchan, "Neurologic complications of HIV disease and their treatment," Topics in HIV Medicine, vol. 18, no. 2, pp. 45-55, 2010.
[158] L. Boven, F. Noorbakhsh, G. Bouma et al., "Brain-derived human immunodeficiency virus-1 Tat exerts differential effects on LTR transactivation and neuroimmune activation," Journal of NeuroVirology, vol. 13, no. 2, pp. 173-184, 2007.

[159] K. Wong, A. Sharma, S. Awasthi et al., "HIV-1 Tat interactions with p300 and PCAF transcriptional coactivators inhibit histone acetylation and neurotrophin signaling through CREB," Journal of Biological Chemistry, vol. 280, no. 10, pp. 9390-9399, 2005.

[160] K. Conant, A. Garzino-Demo, A. Nath et al., "Induction of monocyte chemoattractant protein-1 in HIV-1 Tatstimulated astrocytes and elevation in AIDS dementia," Proceedings of the National Academy of Sciences of the United States of America, vol. 95, no. 6, pp. 3117-3121, 1998.

[161] M. V. Aksenova, J. M. Silvers, M. Y. Aksenov et al., "HIV1 Tat neurotoxicity in primary cultures of rat midbrain fetal neurons: changes in dopamine transporter binding and immunoreactivity," Neuroscience Letters, vol. 395, no. 3, pp. 235-239, 2006.

[162] L. Buscemi, D. Ramonet, and J. D. Geiger, "Human immunodeficiency virus type-1 protein Tat induces tumor necrosis factor- $\alpha$-mediated neurotoxicity," Neurobiology of Disease, vol. 26, no. 3, pp. 661-670, 2007.

[163] O. Kutsch, J. W. Oh, A. Nath, and E. N. Benveniste, "Induction of the chemokines interleukin-8 and IP-10 by human immunodeficiency virus type 1 Tat in astrocytes," Journal of Virology, vol. 74, no. 19, pp. 9214-9221, 2000.

[164] R. Williams, H. Yao, N. K. Dhillon, and S. J. Buch, "HIV-1 Tat co-operates with IFN- $\gamma$ and TNF- $\alpha$ to increase CXCL10 in human astrocytes," PLoS ONE, vol. 4, no. 5, article e5709, 2009.

[165] A. C. Bratanich, C. Liu, J. C. McArthur et al., "Brain-derived HIV-1 Tat sequences from AIDS patients with dementia show increased molecular heterogeneity," Journal of NeuroVirology, vol. 4, no. 4, pp. 387-393, 1998.

[166] M. Mayne, A. C. Bratanich, P. Chen, F. Rana, A. Nath, and C. Power, "HIV-1 Tat molecular diversity and induction of TNF- $\alpha$ : implications for HIV-induced neurological disease," NeuroImmunoModulation, vol. 5, no. 3-4, pp. 184-192, 1998.

[167] D. Cowley, L. R. Gray, S. L. Wesselingh, P. R. Gorry, and M. J. Churchill, "Genetic and functional heterogeneity of CNS-derived Tat alleles from patients with HIV-associated dementia," Journal of NeuroVirology, vol. 17, no. 1, pp. 7081,2011 .

[168] T. H. Hogan, D. L. Stauff, F. C. Krebs, S. Gartner, S. J. Quiterio, and B. Wigdahl, "Structural and functional evolution of human immunodeficiency virus type 1 long terminal repeat CCAAT/enhancer binding protein sites and their use as molecular markers for central nervous system disease progression," Journal of NeuroVirology, vol. 9, no. 1, pp. 55$68,2003$.

[169] H. L. Ross, M. R. Nonnemacher, T. H. Hogan et al., "Interaction between CCAAT/enhancer binding protein and cyclic amp response element binding protein 1 regulates human immunodeficiency virus type 1 transcription in cells of the monocyte/macrophage lineage," Journal of Virology, vol. 75, no. 4, pp. 1842-1856, 2001.

[170] M. R. Nonnemacher, B. P. Irish, Y. Liu, D. Mauger, and B. Wigdahl, "Specific sequence configurations of HIV-1 LTR G/C box array result in altered recruitment of Sp isoforms and correlate with disease progression," Journal of Neuroimmunology, vol. 157, no. 1-2, pp. 39-47, 2004.

[171] L. Li, B. Aiamkitsumrit, V. Pirrone et al., "Development of co-selected single nucleotide polymorphisms in the viral 
promoter precedes the onset of human immunodeficiency virus type 1-associated neurocognitive impairment," Journal of NeuroVirology, vol. 17, no. 1, pp. 92-109, 2011.

[172] J. B. Johnston, K. Zhang, C. Silva et al., "HIV-1 Tat neurotoxicity is prevented by matrix metalloproteinase inhibitors," Annals of Neurology, vol. 49, no. 2, pp. 230-241, 2001.

[173] C. Silva, K. Zhang, S. Tsutsui, J. K. Holden, M. J. Gill, and C. Power, "Growth hormone prevents human immunodeficiency virus-induced neuronal p53 expression," Annals of Neurology, vol. 54, no. 5, pp. 605-614, 2003.

[174] T. H. Burdo, S. Gartner, D. Mauger, and B. Wigdahl, "Regionspecific distribution of human immunodeficiency virus type 1 long terminal repeats containing specific configurations of CCAAT/enhancer-binding protein site II in brains derived from demented and nondemented patients," Journal of NeuroVirology, vol. 10, supplement 1, pp. 7-14, 2004.

[175] T. H. Hogan, M. R. Nonnemacher, F. C. Krebs, A. Henderson, and B. Wigdahl, "HIV-1 Vpr binding to HIV-1 LTR C/ EBP cis-acting elements and adjacent regions is sequencespecific," Biomedicine and Pharmacotherapy, vol. 57, no. 1, pp. 41-48, 2003.

[176] S. N. Richter and G. Palù, "Inhibitors of HIV-1 Tat-mediated transactivation," Current Medicinal Chemistry, vol. 13, no. 11, pp. 1305-1315, 2006.

[177] H. Siomi, H. Shida, M. Maki, and M. Hatanaka, "Effects of a highly basic region of human immunodeficiency virus Tat protein on nucleolar localization," Journal of Virology, vol. 64, no. 4, pp. 1803-1807, 1990.

[178] I. Choudhury, J. Wang, S. Stein, A. Rabson, and M. J. Leibowitz, "Translational effects of peptide antagonists of Tat protein of human immunodeficiency virus type 1," Journal of General Virology, vol. 80, part 3, pp. 777-782, 1999.

[179] V. Cecchetti, C. Parolin, S. Moro et al., "6-aminoquinolones as new potential anti-HIV agents," Journal of Medicinal Chemistry, vol. 43, no. 20, pp. 3799-3802, 2000.

[180] S. Richter, C. Parolin, B. Gatto et al., "Inhibition of human immunodeficiency virus type 1 Tat-trans-activation-responsive region interaction by an antiviral quinolone derivative," Antimicrobial Agents and Chemotherapy, vol. 48, no. 5, pp. 1895-1899, 2004.

[181] H. Y. Mei, M. Cui, A. Heldsinger et al., "Inhibitors of proteinRNA complexation that target the RNA: specific recognition of human immunodeficiency virus type 1 TAR RNA by small organic molecules," Biochemistry, vol. 37, no. 40, pp. 1420414212, 1998.

[182] M. Stevens, C. Pannecouque, E. de Clercq, and J. Balzarini, "Inhibition of human immunodeficiency virus by a new class of pyridine oxide derivatives," Antimicrobial Agents and Chemotherapy, vol. 47, no. 9, pp. 2951-2957, 2003.

[183] M. Stevens, C. Pannecouque, E. de Clercq, and J. Balzarini, "Novel human immunodeficiency virus (HIV) inhibitors that have a dual mode of anti-HIV action," Antimicrobial Agents and Chemotherapy, vol. 47, no. 10, pp. 3109-3116, 2003.

[184] E. de Clercq and D. Schols, "Inhibition of HIV infection by CXCR4 and CCR5 chemokine receptor antagonists," Antiviral Chemistry and Chemotherapy, vol. 12, supplement 1, pp. 19-31, 2001.

[185] N. Gelus, F. Hamy, and C. Bailly, "Molecular basis of HIV-1 TAR RNA specific recognition by an acridine Tat-antagonist," Bioorganic and Medicinal Chemistry, vol. 7, no. 6, pp. 10751079, 1999.
[186] S. Wang, P. W. Huber, M. Cui, A. W. Czarnik, and H. Y. Mei, "Binding of neomycin to the TAR element of HIV1 RNA induces dissociation of Tat protein by an allosteric mechanism," Biochemistry, vol. 37, no. 16, pp. 5549-5557, 1998.

[187] K. Hamasaki and A. Ueno, "Aminoglycoside antibiotics, neamine and its derivatives as potent inhibitors for the RNA-protein interactions derived from HIV-1 activators," Bioorganic and Medicinal Chemistry Letters, vol. 11, no. 4, pp. 591-594, 2001.

[188] J. M. Jacque, K. Triques, and M. Stevenson, "Modulation of HIV-1 replication by RNA interference," Nature, vol. 418, no. 6896, pp. 435-438, 2002.

[189] P. Corbeau, "Interfering RNA and HIV: reciprocal interferences," PLoS Pathogens, vol. 4, no. 9, article e1000162, 2008.

[190] A. J. Fulcher and D. A. Jans, "The HIV-1 Tat transactivator protein: a therapeutic target?" IUBMB Life, vol. 55, no. 12, pp. 669-680, 2003.

[191] M. Giacca, "The HIV-1 Tat protein: a multifaceted target for novel therapeutic opportunities," Current Drug Targets, vol. 4, no. 4, pp. 277-285, 2004.

[192] V. Pirrone, B. Wigdahl, and F. C. Krebs, "The rise and fall of polyanionic inhibitors of the human immunodeficiency virus type 1," Antiviral Research, vol. 90, no. 3, pp. 168-182, 2011.

[193] M. Rusnati, G. Taraboletti, C. Urbinati et al., "Thrombospondin-1/HIV-1 Tat protein interaction: modulation of the biological activity of extracellular Tat," FASEB Journal, vol. 14, no. 13, pp. 1917-1930, 2000.

[194] A. Corallini, M. Betti, M. Rusnati et al., "Characterization of the effects of two polysulfonated distamycin A derivatives, PNU145156E and PNU153429, on HIV type 1 Tat protein," AIDS Research and Human Retroviruses, vol. 14, no. 17, pp. 1561-1571, 1998.

[195] K. Watson, N. J. Gooderham, D. S. Davies, and R. J. Edwards, "Interaction of the transactivating protein HIV-1 Tat with sulphated polysaccharides," Biochemical Pharmacology, vol. 57, no. 7, pp. 775-783, 1999.

[196] H. Zhao, J. Li, and L. Jiang, "Inhibition of HIV-1 TAR RNA-Tat peptide complexation using poly(acrylic acid)," Biochemical and Biophysical Research Communications, vol. 320, no. 1, pp. 95-99, 2004.

[197] L. W. Meredith, H. Sivakumaran, L. Major, A. Suhrbier, and D. Harrich, "Potent inhibition of HIV-1 replication by a Tat mutant," PLoS ONE, vol. 4, no. 11, article e7769, 2009.

[198] C. Ulich, D. Harrich, P. Estes, and R. B. Gaynor, "Inhibition of human immunodeficiency virus type 1 replication is enhanced by a combination of transdominant Tat and Rev proteins," Journal of Virology, vol. 70, no. 7, pp. 4871-4876, 1996.

[199] C. Rossi, P. G. Balboni, M. Betti et al., "Inhibition of HIV1 replication by a Tat transdominant negative mutant in human peripheral blood lymphocytes from healthy donors and HIV-1-infected patients," Gene Therapy, vol. 4, no. 11, pp. 1261-1269, 1997.

[200] A. Caputo, M. P. Grossi, R. Bozzini et al., "Inhibition of HIV-1 replication and reactivation from latency by Tat transdominant negative mutants in the cysteine rich region," Gene Therapy, vol. 3, no. 3, pp. 235-245, 1996.

[201] G. Goldstein and J. J. Chicca II, "A universal anti-HIV-1 Tat epitope vaccine that is fully synthetic and self-adjuvanting," Vaccine, vol. 28, no. 4, pp. 1008-1014, 2010.

[202] W. Huang, G. Varani, and G. P. Drobny, ${ }^{13} \mathrm{C} /{ }^{15} \mathrm{~N}-{ }^{19} \mathrm{~F}$ intermolecular REDOR NMR study of the interaction of TAR 
RNA with Tat peptides," Journal of the American Chemical Society, vol. 132, no. 50, pp. 17643-17645, 2010.

[203] A. Davidson, K. Patora-Komisarska, J. A. Robinson, and G. Varani, "Essential structural requirements for specific recognition of HIV TAR RNA by peptide mimetics of Tat protein," Nucleic Acids Research, vol. 39, no. 1, pp. 248-256, 2011.

[204] V. Pirrone, N. Thakkar, J. M. Jacobson, B. Wigdahl, and F. C. Krebs, "Combinatorial approaches to the prevention and treatment of HIV-1 infection," Antimicrobial Agents and Chemotherapy, vol. 55, no. 5, pp. 1831-1842, 2011.

[205] S. Biglione, S. A. Byers, J. P. Price et al., "Inhibition of HIV-1 replication by $\mathrm{P}-\mathrm{TEFb}$ inhibitors $\mathrm{DRB}$, seliciclib and flavopiridol correlates with release of free $\mathrm{P}-\mathrm{TEFb}$ from the large, inactive form of the complex," Retrovirology, vol. 4, article 47, 2007.

[206] J. Bai, J. Sui, R. Y. Zhu et al., "Inhibition of Tat-mediated transactivation and HIV-1 replication by human antihCyclinT1 intrabodies," Journal of Biological Chemistry, vol. 278, no. 3, pp. 1433-1442, 2003.

[207] K. Fujinaga, D. Irwin, M. Geyer, and B. M. Peterlin, "Optimized chimeras between kinase-inactive mutant Cdk9 and truncated cyclin $\mathrm{T} 1$ proteins efficiently inhibit Tat transactivation and human immunodeficiency virus gene expression," Journal of Virology, vol. 76, no. 21, pp. 10873-10881, 2002.

[208] J. H. N. Yik, R. Chen, R. Nishimura, J. L. Jennings, A. J. Link, and Q. Zhou, "Inhibition of P-TEFb (CDK9/cyclin T) kinase and RNA polymerase II transcription by the coordinated actions of HEXIM1 and 7SK snRNA," Molecular Cell, vol. 12, no. 4, pp. 971-982, 2003.

[209] J. H. N. Yik, R. Chen, A. C. Pezda, C. S. Samford, and Q. Zhou, "A human immunodeficiency virus type 1 Tat-like arginine-rich RNA-binding domain is essential for HEXIM1 to inhibit RNA polymerase II transcription through 7SK snRNA-mediated inactivation of P-TEFb," Molecular and Cellular Biology, vol. 24, no. 12, pp. 5094-5105, 2004.

[210] A. Dorr, V. Kiermer, A. Pedal et al., "Transcriptional synergy between Tat and PCAF is dependent on the binding of acetylated Tat to the PCAF bromodomain," EMBO Journal, vol. 21, no. 11, pp. 2715-2723, 2002.

[211] T. Ammosova, R. Berro, M. Jerebtsova et al., "Phosphorylation of HIV-1 Tat by CDK2 in HIV-1 transcription," Retrovirology, vol. 3, article 78, 2006.

[212] C. Chiao, T. Bader, J. E. Stenger, W. Baldwin, J. Brady, and J. C. Barrett, "HIV type 1 Tat inhibits tumor necrosis factor $\alpha$-induced repression of tumor necrosis factor receptor p55 and amplifies tumor necrosis factor $\alpha$ activity in stably Tat-transfected HeLa cells," AIDS Research and Human Retroviruses, vol. 17, no. 12, pp. 1125-1132, 2001.

[213] M. A. Munoz-Fernandez, J. Navarro, E. Obregon et al., "Immunological and virological markers of disease progression in HIV- infected children," Acta Paediatrica, vol. 421, pp. 46-51, 1997. 

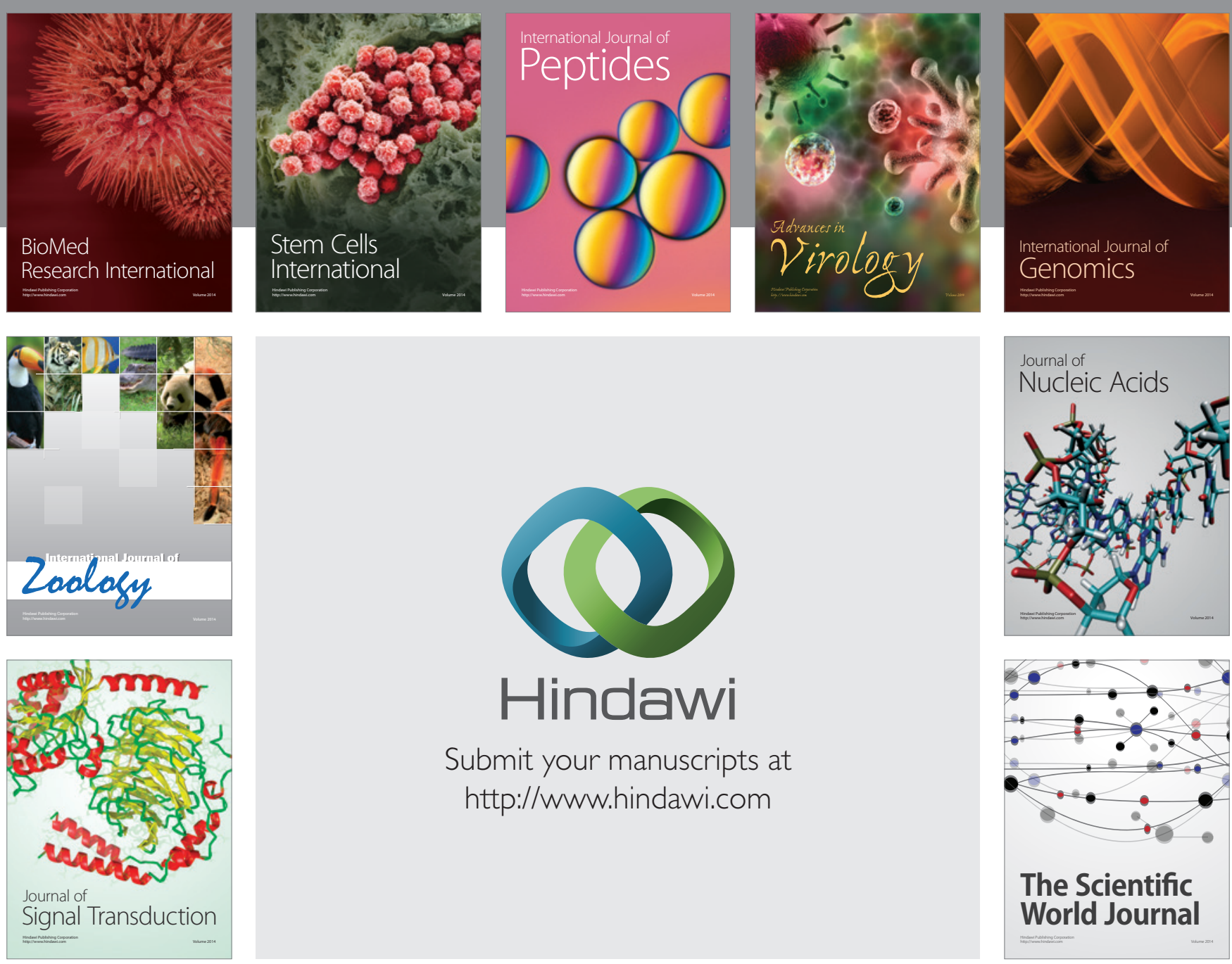

Submit your manuscripts at

http://www.hindawi.com
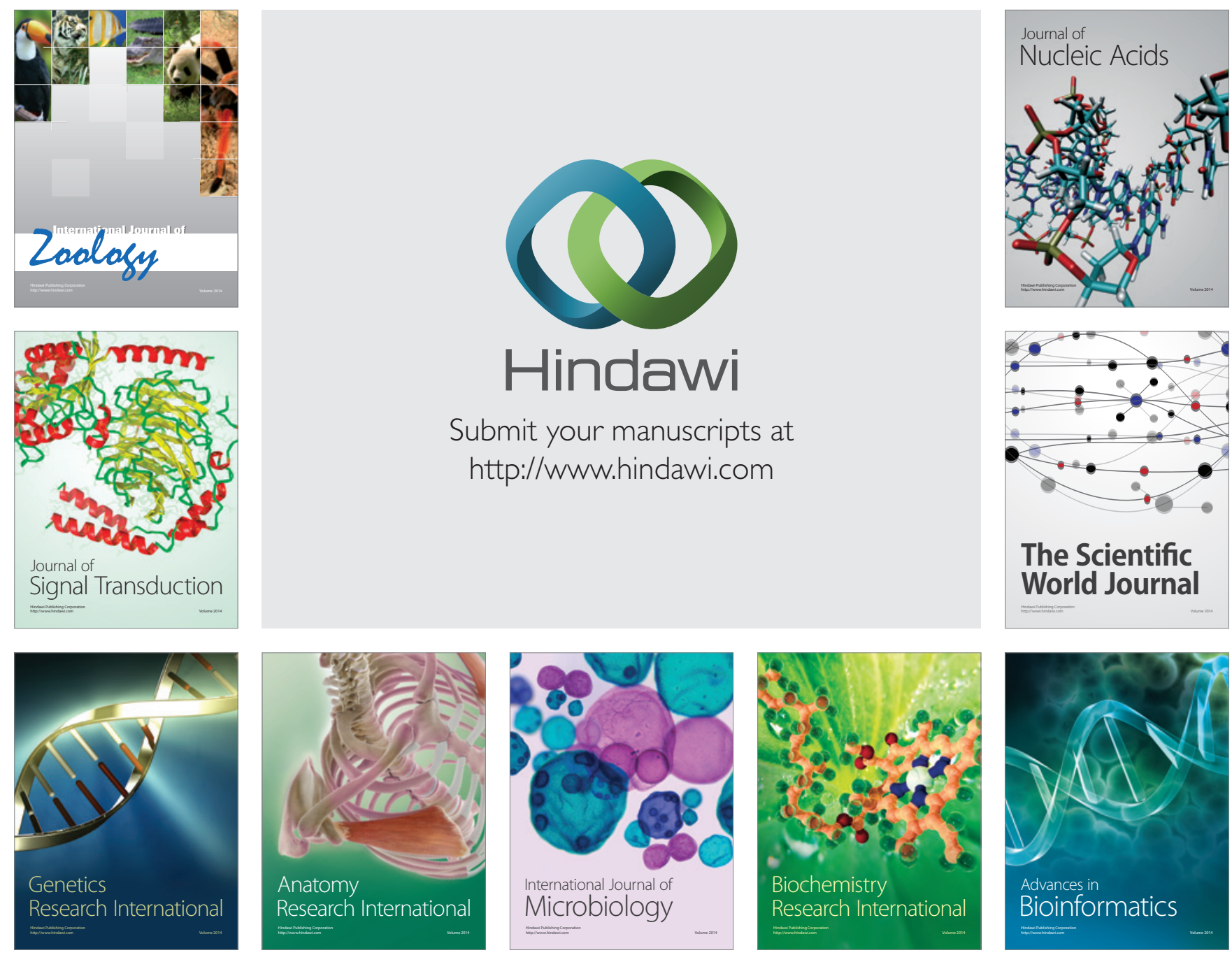

The Scientific World Journal
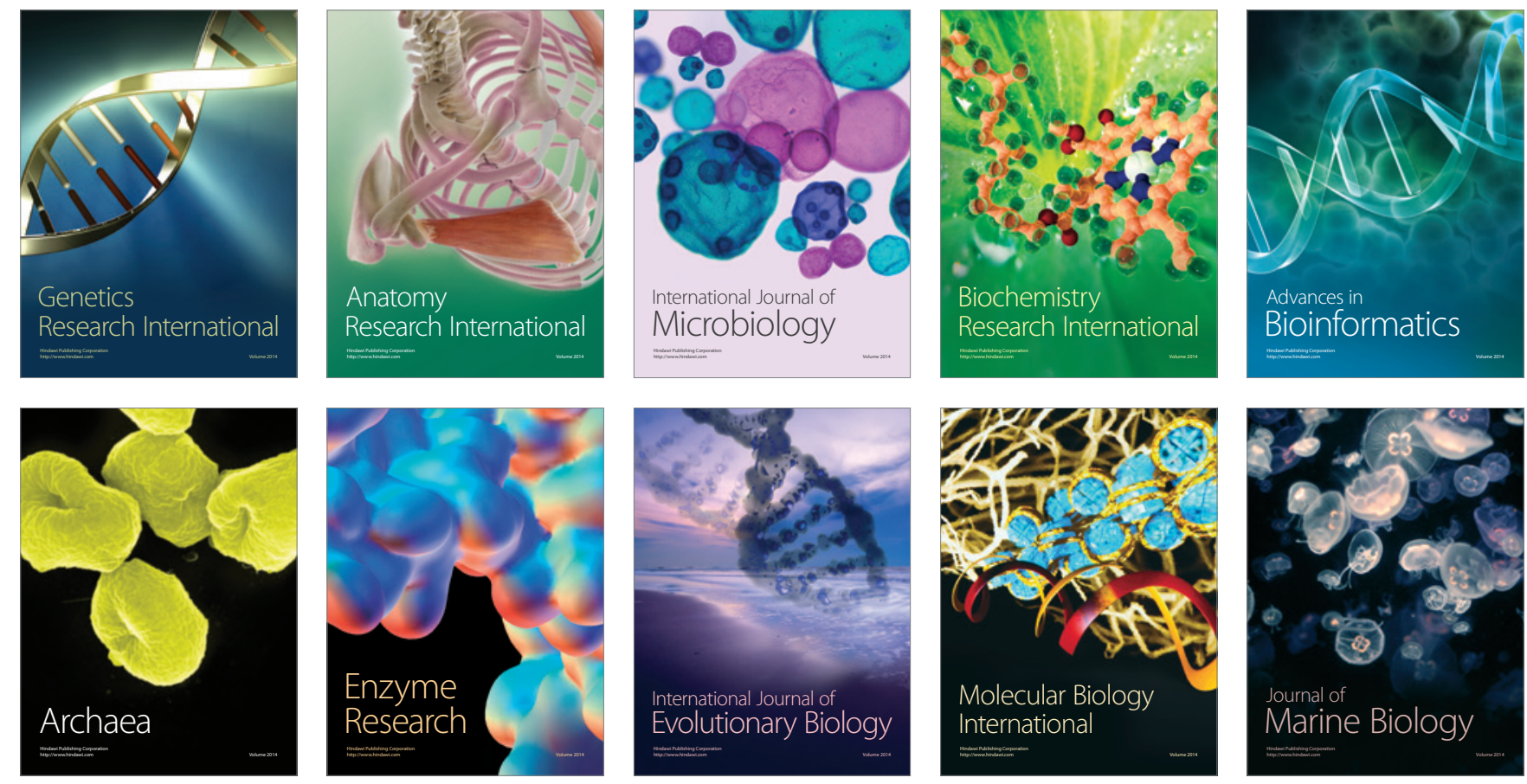